\title{
Survey paper: achievements and perspectives of community resilience approaches to societal systems
}

\author{
Yusuke Toyoda ${ }^{1}$ (iD
}

Received: 1 October 2020 / Accepted: 6 May 2021 / Published online: 18 May 2021

(c) The Author(s) 2021

\begin{abstract}
The term resilience has become a buzzword with a multitude of definitions, and several studies have exerted efforts in conceptualizing it. For further academic progress, discussions on community resilience need to shift from conceptualization to operationalization. In this context, I aim to synthesize academic contributions and provide future perspectives of studies on community resilience approaches, focusing on societal systems. First, I demonstrate the general trend of community resilience research, which leads to a general analytical framework for these studies. Next, I present the results of a survey of influential studies based on this framework and discuss recent achievements in community resilience in relation to the following six elements: social, information, competence, economic, spatial, and natural. From the survey results, I suggest two perspectives: (1) the harmonization of gears for resilience and community resilience sub-elements, including equitable resilience, and (2) inactive resident pursuits of roles in community resilience. Finally, I show the potential contributions of regional science to this topic highlighting its strengths in interdisciplinary approaches based on spatial and temporal scales.
\end{abstract}

Keywords Community resilience $\cdot$ Societal system $\cdot$ Perspective $\cdot$ Document survey $\cdot$ Regional science

JEL Classification $\mathrm{Z} 00 \cdot \mathrm{Z} 13 \cdot \mathrm{Z} 18$

Yusuke Toyoda

toyoday@fc.ritsumei.ac.jp

1 College of Policy Science, Ritsumeikan University, 2-150 Iwakura-cho, Ibaraki,

Osaka 567-8570, Japan 


\section{Community resilience encompassing multiple disciplines}

\subsection{Pluralism to change resilience from Jargon to Buzzword}

Resilience constitutes a tapestry of definitions and meanings with little orthodoxy in conceptualization and application, and this vagueness accounts for much of its appeal in policy (Cutter et al. 2016). In a series of prominent disasters, funding has stimulated both local and global stakeholders to inspire engagement in practical resilience. Wilson (2012) maintained that the notion of resilience might be starting to replace sustainability as the new political and policymaking buzzword since the early $2000 \mathrm{~s}$.

Recently, the popularity of the term has been present in academic domains as well. Alexander (2013) traced back the evolution of the term resilience, which came from the Latin resilire and resilio ("bounce [back]") in AD 35. Meanwhile, Palekiene et al. (2015) showed that the notion of resilience originated from the 1824 edition of Encyclopedia Britannica. On the other hand, studies on resilience might have started just in the mid-twentieth century (Goldstein and Brooks 2006). According to Cutter et al. (2008), Holling (1973, p. 14) was the first scholar to describe resilience as "a measure of the persistence of systems and of their ability to absorb change and disturbance and still maintain the same relationships between populations or state variables." As in the practice arena, the pluralism or ambiguity in resilience is considered as more conducive for promoting interdisciplinary dialog (such as in Alexander 2013 and Olsson et al. 2015), and some researchers such as Quinlan et al. (2016) examined how resilience is defined in different domains. However, for a comprehensible discussion, this paper defines resilience as a system's ability to respond and recover from disasters, which includes inherent conditions that allow such a system to deal with aftereffects as well as implement adaptive postevent processes that enhance its aptitude in reorganizing, changing, and learning as it responds to threats (adopted mainly from Cutter et al. 2008, p. 599). This is because the term seems to adopt a conceptual and general definition, which includes shared components discussed by the majority of scholars, some of whom have defined it more specifically or applicably in practice to reach certain objectives.

Nevertheless, resilience currently has a wide influence in different academic domains ranging from mechanics, ecology, and psychology to disaster risk reduction sciences, sustainability sciences, and others. Cutter et al. (2016) stated that the health sciences focus on what makes individuals and community health systems resilient before and after disasters while biological and natural sciences provide insights into the properties of environments and their ability to absorb shocks and rebound. Engineering also discusses the resilience of buildings and infrastructure. Similarly, sociology provides an understanding of what makes social units resilient as well as their different inherent capabilities. In addition, economics performs sector-based analyses while spatial sciences (planning and geography) discuss and compare local and global resilience patterns and processes. With such vagueness, resilience may link discussions among different disciplines while creating communication roadblocks. 
Besides its definition, its usage and categorization also vary. The common usage of resilience allows for some flexibility when placed in declarative statements. For example, Ayyub (2014) provided two meaningful forms that are structurally identical: (1) infrastructure resilience is desirable, and (2) storm resilience is desirable. The former statement connects resilience to the quality of infrastructure; whereas, the latter links resilience to the quality of whatever is affected by a storm. In addition, scrutinizing previous studies reveals another quality of resistance: (3) information resilience is desirable. This links resilience with the capacity to make use of information by anyone who is affected by an external disruption.

Moreover, the concept of resilience could be classified according to focus (Manyena et al. 2019), that is, resilience focuses on either a process (capacity building, quality, etc.) or an outcome (characteristic, recovery period, etc.). Meanwhile, Cutter et al. (2016) combined both and defined the former as adaptive resilience and the latter as inherent resilience. However, the aforementioned study maintained that process is also a measurable outcome. With external shocks and feedback systems, the concept of resilience encompasses dynamic systems of inherent and adaptive resilience. As mentioned above, this feature allows the term to connect as many different scholars as possible while making itself complex and communication among scholars is difficult. However, since some influential scholars have synthesized its conceptualization as discussed above, the discussion on resilience is shifting from conceptualization to operationalization in various contexts (Manyena et al. 2019).

\subsection{General characteristics of community resilience}

Resilience as a concept could be applied to any object and idea, such as resilient machines and resilient economy. Among various targets, I demonstrate the academic progress on the resilience of (local) communities, the significance of which has been highlighted in recent works. For example, in disaster management, we need to work with neighborhoods such as resident associations to identify their needs and appropriate mitigation and recovery approaches (Norris et al. 2008; Toyoda and Kanegae 2014; to mention a few). Discussions regarding disaster management challenges and complexities frequently allude to community resilience as an important ingredient (Norris et al. 2008). The concept is also becoming the de facto framework for enhancing community-level disaster preparedness, response, and recovery in the short-term and climate-change adaptation in the long-term (Cutter et al. 2014).

Shifting community resilience to an analytical level, Toyoda (2020) demonstrated that resilience can be viewed from three perspectives: stability (absorption), recovery (bouncing back), and transformation (adaptability). Recovery rarely occurs in the direction of a preexisting state, therefore, necessitating some consideration for regaining life functions as exhibited by one's experiences in evacuation shelters. Moreover, Barnes et al. (2020) explained two types of adaptability: adaptation in the form of incremental adaptation (allowing existing system structures to absorb, accommodate, or embrace change) and transformation in the form of transformational adaptation (altering dominant relationships). Therefore, at the operational level, (community) resilience could be discussed from four viewpoints: stability 
(keeping the community's pivotal functions by reducing loss through mitigation, preparedness, and immediate response), recovery (recovering life functions), adaptability (changing existing practices and behaviors incrementally), and transformability (altering existing practices or behaviors that allow for system structure change).

Another distinction within (community) resilience is specified resilience against known risks and general resilience for unknown ones (or all-hazard approaches). Both, according to Cavallo and Ireland (2014), must be addressed by disaster risk reduction strategies to prepare the wider community for both predictable and unpredictable risks. Cavallo and Ireland (2014) also stated that many studies have focused on specified resilience and that the challenge to study general resilience has continued because of the unpredictability of future disasters and difficulties in ensuring that the wider community can access risk-specific information. As shown below, the main topic of most of the literature reviewed in this paper has been specified resilience.

In the discussion of community resilience, community should be defined first, as variations in its meaning complicate the concept of community resilience (Norris et al. 2008; Murphy 2007 also delineated this issue in the context of community emergency management). While much research on community resilience has considered communities as geographically defined people, community is a multilayered notion (Mulligan et al. 2016). Dynamic interactions occur between communities and can operate simultaneously across multiple scales (Sharifi 2016). Moreover, as stated by Miller Hesed and Paolisso (2015), social-ecological factors have substantially different effects on local vulnerability, even among communities with similar demographics and climate-related risks, and social and political isolation obstructs adaptive capacity, which exacerbates local vulnerability. Therefore, while this study accepts a variety of community units for community resilience, it defines community as a geographically based population and groups comprised of such population (or a part thereof) from the level of neighborhood associations to that of counties. Meanwhile, the resilience of imagined or virtual communities and interest- or kinship-based communities is beyond the scope of this study, as academic research has rarely considered these types in the context of community resilience.

When defining community resilience, it is important to differentiate between community resilience and other similar terms, such as urban resilience, city resilience, rural resilience, and regional resilience, which are all orthodox theories that deal with certain territories. In general, non-urban areas are categorized as either rural or suburban. However, Chelleri and Olazabal's (2012) study clearly identified the conceptual differences between urban and rural resilience, thereby stating that the former refers to the ability of city or urban systems "to adjust in the face of uncertainty and surprise" and "capitalize on positive opportunities the future may bring," whereas, the latter refers to the ability "to preserve a satisfactory standard of living as a result of the capacity of a rural region to adapt to mutable external conditions" (p. 54). Later in this paper, community resilience is discussed in the context of both urban and rural areas. In my discussion, I include both urban and rural resilience within the category of community resilience despite their differences in meaning. Some scholars differentiated between "urban community resilience" (Archer et al. 2020) and "rural community resilience" in their analysis (Wilson 2010). A 
similar relationship exists between community and regional resilience. Dabson (2015) stated that a focus on community resilience has to be complemented by an understanding that the effects of disasters rarely stay within local, urban, rural, or even state jurisdictional boundaries when discussing regional resilience. Therefore, regional resilience focuses on the integration of processes, actions, and decisions across territories, while community resilience mainly focuses on a single territorial unit.

\subsection{Community resilience for the neighborhood societal realm}

Several recent synthesis papers have traced back the academic discussion on community resilience. Norris et al. (2008) indicated that there have been two discernible pathways to the present state of knowledge. One has been more concerned with how community resilience prevents community members' disaster-related health or mental health problems. The other has focused more on how community resilience describes effective organizational behavior and disaster management. These ideas overlap with Alexander's (2013), who argued that psychology concentrates on the individual, although influenced by their social, cultural, and physical environment, while sociology is the science of social relationships. This intersection of ideas between the two disciplines, while mostly discussing community resilience based on disasters and crises, has not always produced a harmonious view of the same phenomena. These summaries show that community resilience was mainly studied in the psychological and societal domain until at least 2013, when Alexander (2013) was published. Hence, in this paper, I focus on the societal domain, which is closer to the academic field of regional science.

Many scholars (such as Norris et al. 2008; Berkes and Ross 2013; Sharifi 2016) have reviewed community resilience definitions and metrics. However, many researchers have also approached community resilience from the perspective of building and applying it to real-world cases (Abramson et al. 2015; Iacoviello and Charney 2014; O'Sullivan et al. 2013). The majority of these studies have yet to be reviewed. Manyena et al. (2019) pointed out that discussions on resilience are transitioning from conceptualization to operationalization. Adopting an operational approach to resilience, Bahadur et al. (2010) scrutinized existing studies on resilience in relation to climate change and disasters and identified the key characteristics of resilient systems. However, community resilience includes several elements closely related to the concept of community, which is reflected in social and economic metrics, etc. A synthesis incorporating these elements would contribute to experts' understanding of this issue. Therefore, it is necessary to review the major academic achievements of operational approaches to "community resilience."

\subsection{Research objectives and structure}

This paper aims to synthesize the academic contributions of community resilience approaches. Academic in this paper refers to contributions mainly through academic documents including journal articles and books and excluding gray documents such 
as (non-)governments' reports and similar materials. Meanwhile, community resilience approach specifically points to how the concept is applied in real-world situations.

The next chapter delineates methods to visualize general trends surrounding the academic discussion on community resilience so that a general document survey framework can be constructed. The results of the document survey related to community resilience approaches are then presented, followed by an explanation of how regional science may contribute to such approaches.

\section{The general trend of academic discussion on community resilience}

This chapter shows the search parameters for the document survey and the trends of the documents followed by two document analysis methods: keyword occurrence analysis and bibliographic analysis. Based on these, the study will present a general analytical framework for community resilience studies.

\subsection{Strengths of VOSviewer and the web of science core collection for the document survey}

To examine the trend of community resilience studies, I used VOSviewer and the Web of Science Core Collection. VOSviewer is a software in which networks of academic documents are constructed and visualized (Van Eck and Waltma 2017). This software can analyze several databases such as the Web of Science Core Collection, Scopus, and others. I chose the Web of Science Core Collection among databases with abstracts and citations. According to Toriya (2017), while Scopus contains a larger number of journals, it only stores documents from 1990 onward; meanwhile, the Web of Science Core Collection contains records from 1900. Moreover, the Web of Science Core Collection allows data selection only if certain quality standards are met, which enables a researcher to retrieve documents from a longer period and search only quality literature.

When searching for the term community resilience, similar terms with the same meaning should not be overlooked. Alexander (2013) argued that "resilience," "resiliency," and "resilient" are the superior descriptors of objectives, intentions, states of mind and body, and behaviors of people and things. I also found that these three terms frequently describe resilience with the same meaning while being used in different ways in terms of grammar. Therefore, for the search keywords, I used not only "community resilience" but also "resilient community" and "community resiliency."

\subsection{Trends in community resilience documents}

\subsubsection{Search parameters}

The search was conducted on April 23, 2020 according to the conditions shown in Table 1. Although the target period was from 1900 to 2019, the list included documents to be published in 2020 but were already publicly available in 2019. Moreover, I corrected some errors in the Web of Science Core Collection data. I extracted 
Table 1 Search Parameters

\begin{tabular}{ll}
\hline Database & Web of Science Core Collection \\
\hline Search Field & All \\
Keyword & "Community Resilience" \\
& or \\
& "Resilient Community" \\
& or \\
& "Community Resiliency" \\
& 1900-2019 \\
Time Span & Article or Review or Proceedings Paper or Book Chapter or Early Access or Book \\
Document Types & SCI-EXPANDED, SSCI, A\&HCI, CPCI-S, CPCI-SSH, BKCI-S, BKCI-SSH, \\
Indexes & ESCI, CCR-EXPANDED, IC \\
\end{tabular}

SCI-EXPANDED Science Citation Index Expanded, SSCI Social Sciences Citation Index, A\&HCI Arts \& Humanities Citation Index, CPCI-S Conference Proceedings Citation Index-Science, SPCI-SSH Conference Proceedings Citation Index-Social Sciences \& Humanities, BKCI-S Book Citation Index-Science, BKCI-SSH Book Citation Index-Social Sciences \& Humanities, ESCI Emerging Sources Citation Index, CCR-EXPANDED Current chemical reactions, IC Index Chemicus

a total of 2,478 documents (hereafter dataset A). I adhered to the following process: to determine links among documents, I checked those selected via bibliographic coupling, which will be explained below (1000 documents, hereafter dataset B). For dataset $\mathrm{B}$, if their citation weights were 100 or higher (category one: 27 documents), I read their full text; if the weights were between 10 and 99 (category two: 302 documents), I read their titles and abstracts first and only checked their full text when I have determined that they can be included in this study. For the other documents (category three: 671 documents), I checked their titles, abstracts, and full text when necessary.

The list in dataset A and Fig. 1 show that community resilience was first mentioned in 1980, and that studies published earlier discussed resilience in the context of ecology. In a study by Richardson (1980), community was defined not in relation to humans but rather plants and animals; and therefore, the study only discussed ecosystem resilience. In 1998, the term "community resilience" first appeared in the context of human society in data from the Web of Science Core Collection. Sonn and Fisher (1998) discussed community resilience in the field of psychology, noting that the majority of research on resilience (not community resilience) has focused on how children respond to adversity. Afterward, researchers gradually started applying the term. Especially in the second decade of this century, the document count increased dramatically, indicating the time when community resilience emerged at the center stage of academic domains.

\subsubsection{Methods for visualizing academic document networks}

Van Eck and Waltma (2014) provided useful explanations for visualizing academic document networks. Such visualization methods include co-citation, bibliographic coupling, and direct citation-which are citation-based bibliometric networks-, keyword co-occurrence, and co-authorship. Based on the document unit, I adopted 


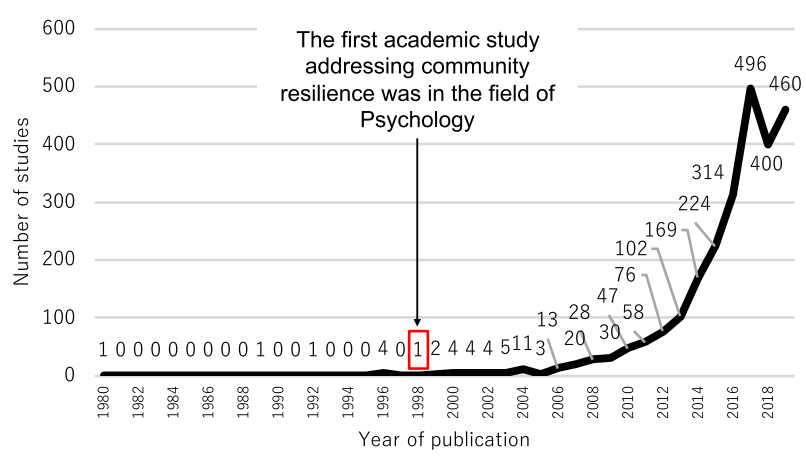

Fig. 1 Annual count of documents using the keyword Community Resilience

keyword co-occurrence and bibliographic coupling. Co-occurrences of keywords refer to the number of publications in which two keywords occur together. The grouping of keywords using this method shows major academic domains that discuss community resilience. On the other hand, bibliographic coupling means that two publications are bibliographically linked if they both cite a third publication, which corresponds to an overlap in publications' reference lists. Because community resilience is discussed in different academic domains, this method would help in finding how documents are linked beyond academic domains.

\subsection{Keyword co-occurrence}

This section presents the method and results of the keyword co-occurrence analysis, which used dataset A. Table 2 shows detailed conditions for the analysis as well as some results. ${ }^{1}$ From this analysis, three clusters were identified that were closely connected (Fig. 2 and Table 3). This means that many documents deal with different community resilience aspects. Despite the link among a variety of keywords, the analysis produced three clusters.

Cluster A (red) concerns societal systems, cluster B (green) pertains to the psychological domain such as mental health, and cluster $\mathrm{C}$ (blue) contains terms on social-ecological systems. In this map, Norris et al.'s (2008) two strands can be identified while the social-ecological systems strand can be divided into two based on focus: one on societal systems (cluster A) and the other on (socio-)ecological systems (Cluster C). Cluster division remains vague but analytically distinctive.

We can infer the locations and types of disasters discussed in previous studies by referring to place and disaster (or hazard) names. For example, Australia was included in Cluster A, Hurricane Katrina and New Orleans were included

\footnotetext{
1 Counting methods, especially full counting versus fractional counting, have been discussed by several studies such as Leydesdorff and Park (2017) and Perianes-Rodriguez et al. (2016). While I recognize the advantages of fractional counting, I adopted full counting to highlight more influential keywords and documents.
} 

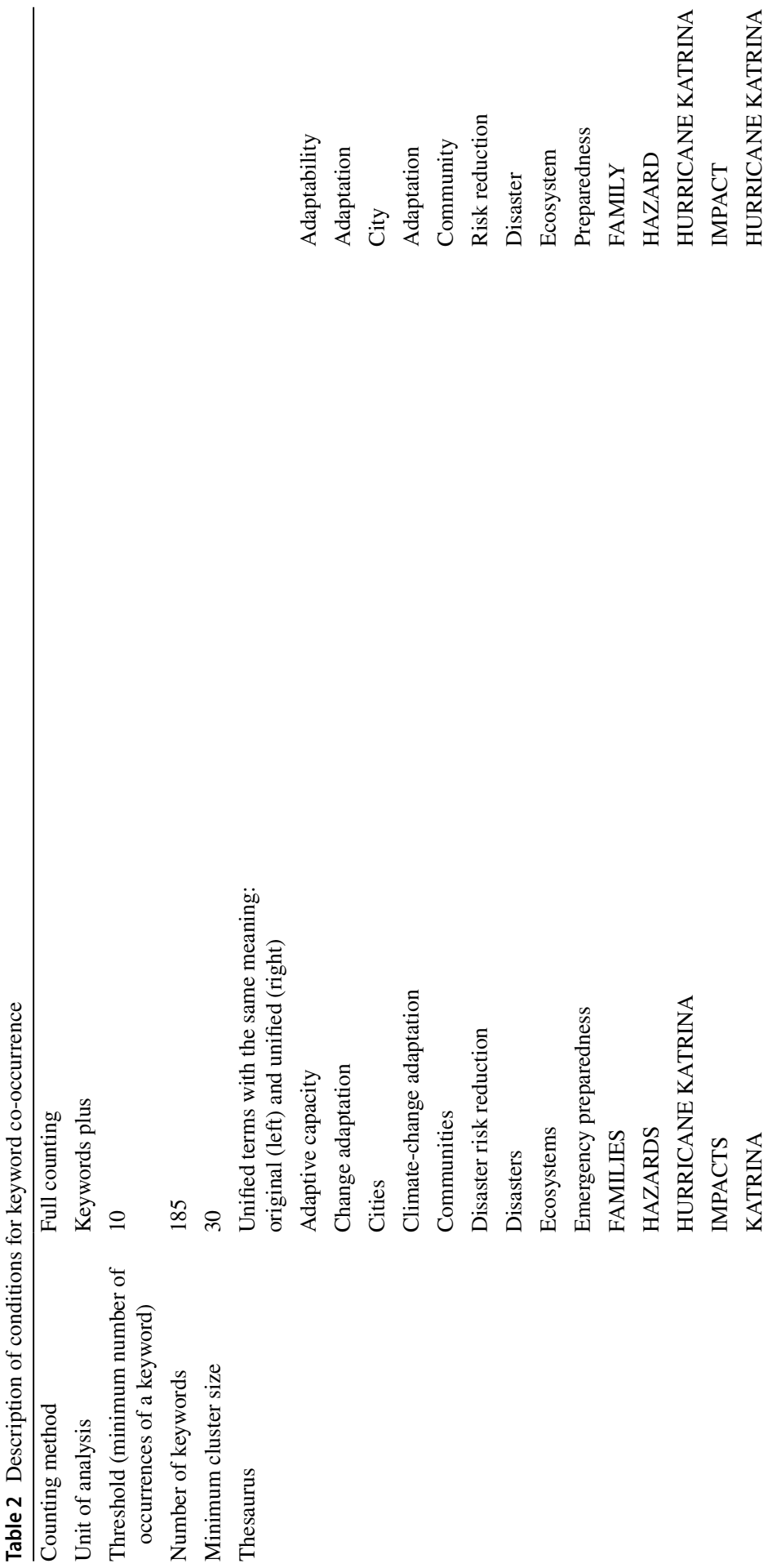


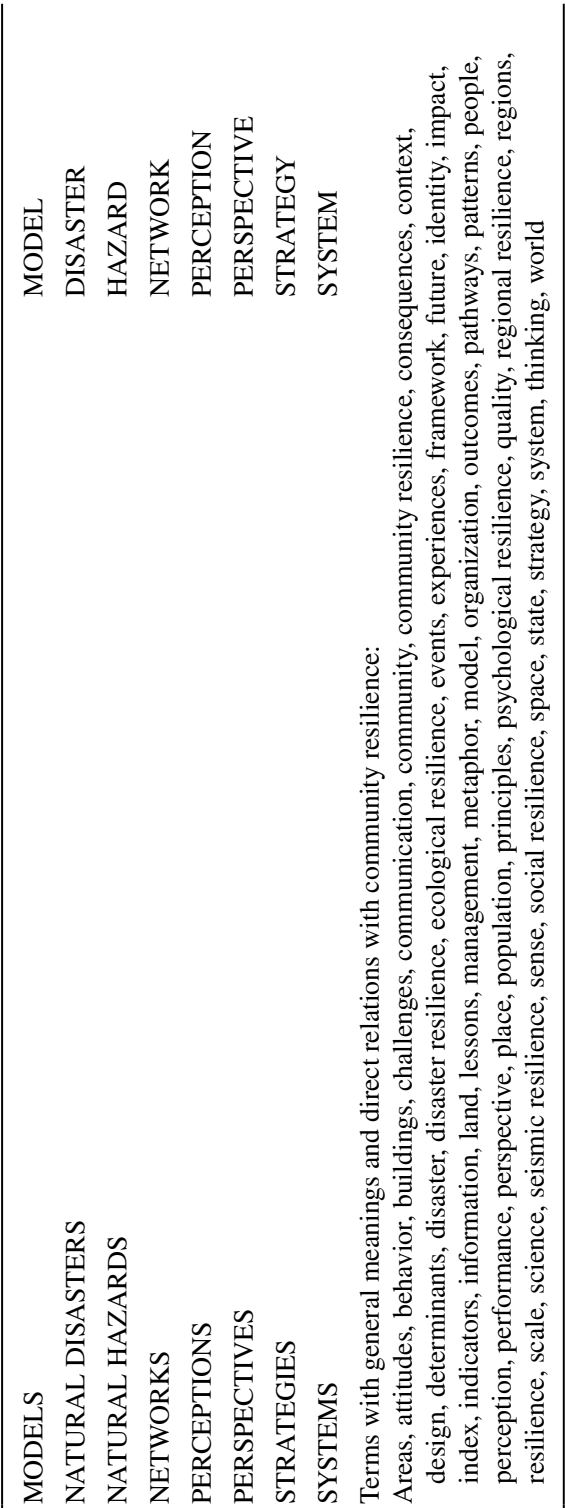

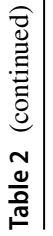

舌 


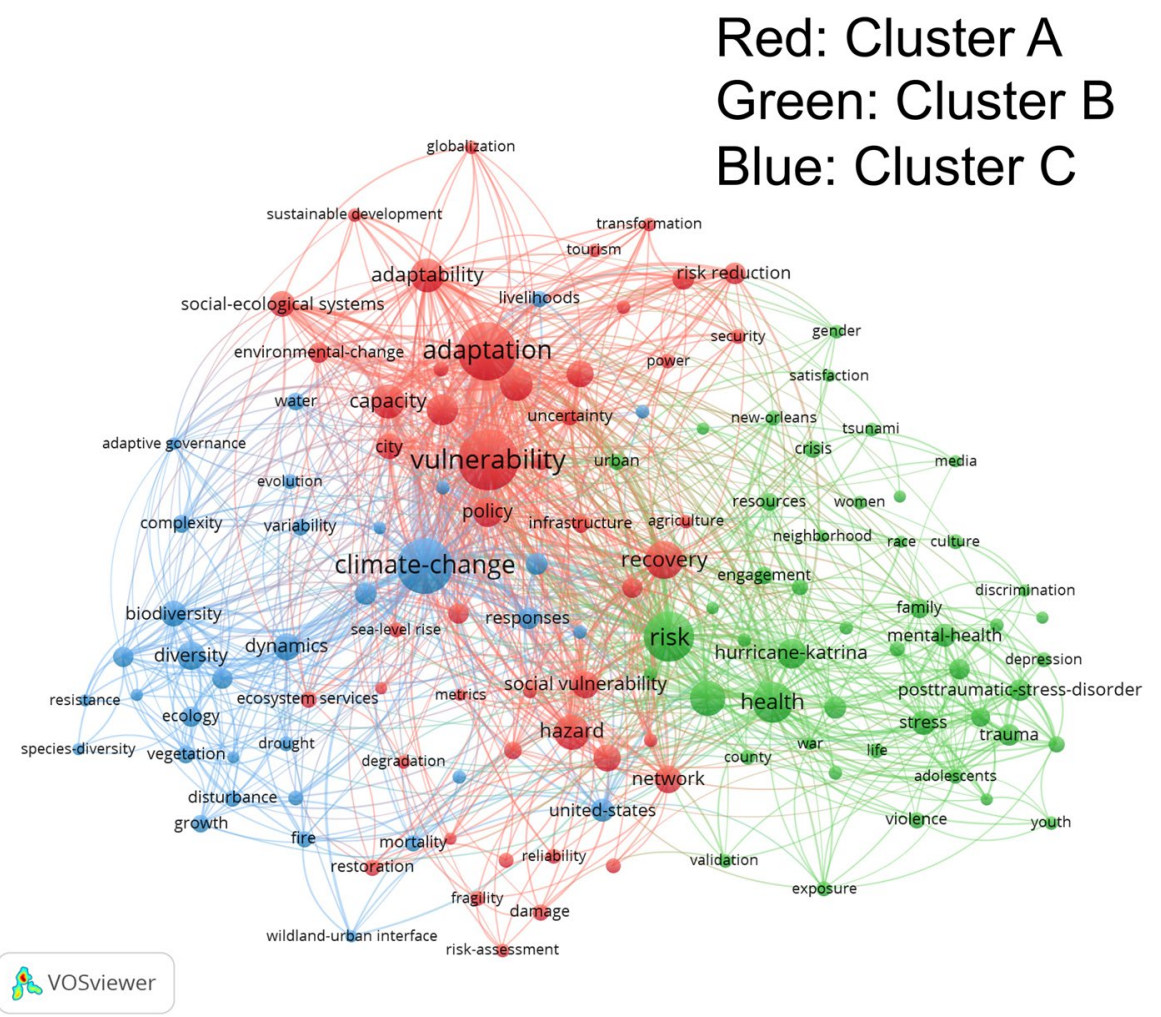

Fig. 2 Results of keyword co-occurrence with clusters

in Cluster B, and the United States was included in Cluster C. If the threshold (the minimum number of occurrences of a keyword) is reduced from 10 to 5 (the cluster categorization is different from the aforementioned analysis, and they cannot be put into three clusters), other keywords are observed, such as New Zealand, China, the United Kingdom, Africa, the Great Barrier Reef, Bangladesh, Canada, England, Europe, and New York City (listed in order of the occurrence). This data implies that studies published in English and included in the Web of Science Core Collection mainly discussed community resilience in the context of some disasters (or hazards) and the areas they affected, such as the North America, Oceania, Europe, Africa and some parts of Asia.

VOSviewer can also show the average publication years in which keywords appeared, from which we can trace periodical trends. Although the differences are subtle, reflecting relative novelty, Fig. 3 shows relatively new occurrences of keywords in Cluster A (societal systems), whose majority of keywords seemed to have appeared since 2015 on average. This implies that Cluster A on societal systems has appeared since Alexander (2013) was published. 
Table 3 Keywords with frequent occurrences of each cluster

\begin{tabular}{|c|c|c|c|c|c|}
\hline Cluster A & Occurrences & Cluster B & Occurrences & Cluster C & Occurrences \\
\hline Vulnerability & 253 & Risk & 168 & Climate change & 204 \\
\hline Adaptation & 229 & Health & 112 & Diversity & 53 \\
\hline Recovery & 95 & Preparedness & 84 & Dynamics & 49 \\
\hline Hazard & 87 & Hurricane-Katrina & 58 & Biodiversity & 47 \\
\hline Adaptability & 78 & Stress & 43 & United-states & 35 \\
\hline Capacity & 78 & Mental health & 37 & Mitigation & 33 \\
\hline Governance & 72 & Public health & 32 & Conservation & 31 \\
\hline Sustainability & 66 & Trauma & 32 & Responses & 31 \\
\hline Policy & 59 & $\begin{array}{l}\text { Posttraumatic-stress- } \\
\text { disorder }\end{array}$ & 31 & Ecosystem & 29 \\
\hline Knowledge & 50 & Children & 27 & Ecology & 28 \\
\hline Network & 49 & Family & 26 & Stability & 28 \\
\hline Social vulnerability & 49 & Social support & 24 & Growth & 23 \\
\hline Earthquake & 48 & Engagement & 23 & Water & 23 \\
\hline $\begin{array}{l}\text { Social-ecological } \\
\text { systems }\end{array}$ & 46 & Crisis & 21 & Vegetation & 22 \\
\hline City & 44 & Resources & 21 & Complexity & 21 \\
\hline Risk reduction & 32 & Migration & 20 & Mortality & 20 \\
\hline Politics & 31 & Urban & 19 & Disturbance & 19 \\
\hline Participation & 30 & Symptoms & 18 & Livelihoods & 19 \\
\hline Climate & 28 & Violence & 18 & Variability & 19 \\
\hline $\begin{array}{l}\text { Environmental } \\
\text { change }\end{array}$ & 28 & Life & 17 & Fire & 18 \\
\hline
\end{tabular}

\subsection{Bibliographic coupling relations}

This section presents the method and results of the bibliographic coupling analysis, which first used dataset $\mathrm{A}$ and produced dataset $\mathrm{B}$, with each document belonging to Cluster 1,2 , or 3 . Table 4 shows the detailed analysis conditions. From this analysis, three clusters were found to be identical (Fig. 4). Before explaining each cluster, I will first describe the general trend. Many of the major articles were published just when community resilience spread as a keyword, that is, from 2006 to 2010, as Fig. 5 shows. On the other hand, while recently published documents tend to receive fewer citations, their publication years do not seem to influence the number of documents selected in this analysis as shown in Fig. 6. Therefore, no consideration for new documents is needed.

All three clusters are also closely interconnected, implying that many of the documents influence other clusters. However, the subsections below highlight major differences among the clusters based on the documents with a high number of citations. After documents with a higher citation count in each cluster were reviewed, they were given the following labels: "Applying Community Resilience to Practice" for Cluster 1, "Constructing Models and Indicators of Community 


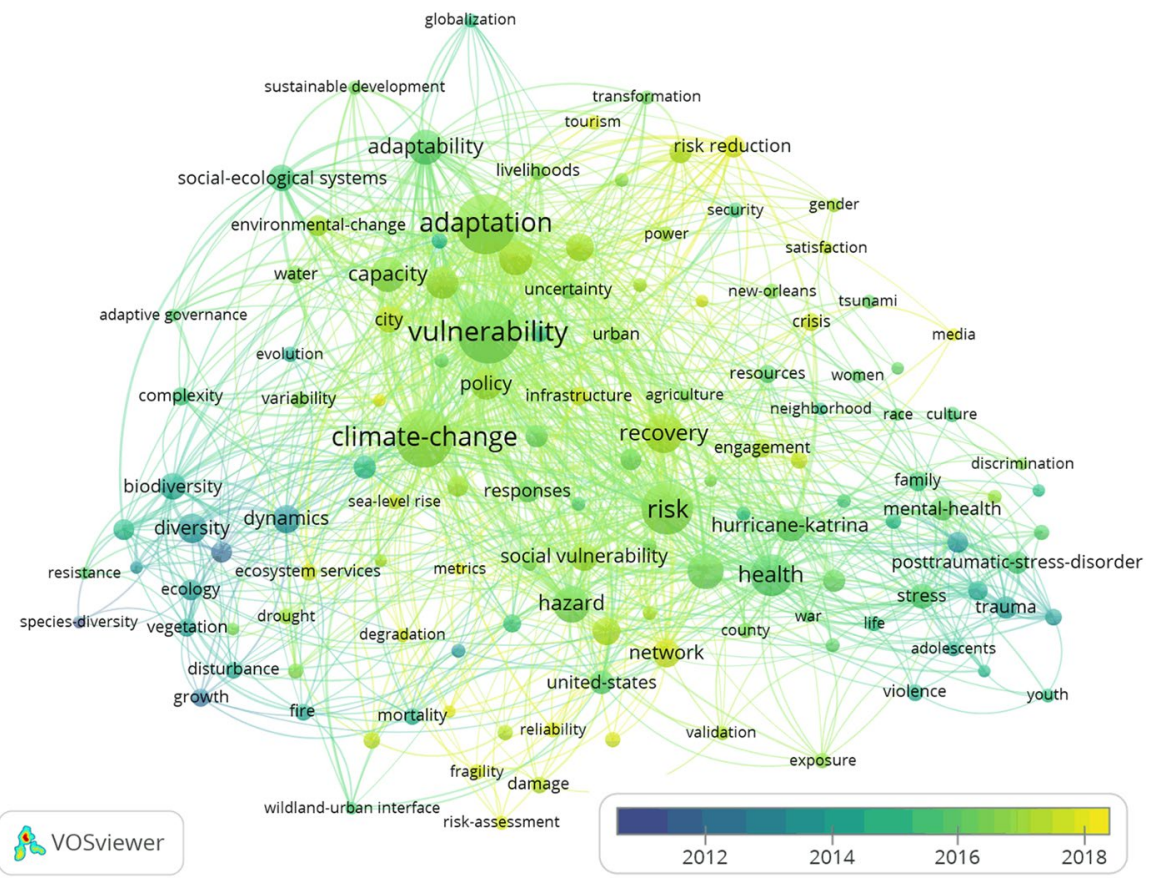

Fig. 3 Results of keyword co-occurrence with the average published year when the keywords appeared

Table 4 Description of conditions for bibliographic coupling relations

\begin{tabular}{ll}
\hline Counting method & Full counting \\
\hline Unit of analysis & Documents \\
$\begin{array}{l}\text { Threshold (minimum number of citations of a docu- } \\
\text { ment) }\end{array}$ & 0 \\
Number of documents & 2478 \\
Number of documents selected & 1000 \\
\hline
\end{tabular}

Resilience" for Cluster 2, and "Conceptualizing Community Resilience" for cluster 3. Since Cluster 3 discusses mostly conceptual matters while Cluster 1 consists of the most applicable issues, the subsections below delineate from Clusters 3 and 2 and end with Cluster 1 (see Table 5).

\subsubsection{Cluster 3: COnceptualizing (Community) resilience}

Cluster 3 (blue) contains 295 documents, including 16 in category one and 98 in category two. Documents in this cluster show an attempt to synthesize or pursue the concept of (community) resilience. This cluster deals with more abstract themes on resilience than others. A summary of some influential documents in this cluster reveals the source of the term and its potential to bridge different academic domains. 


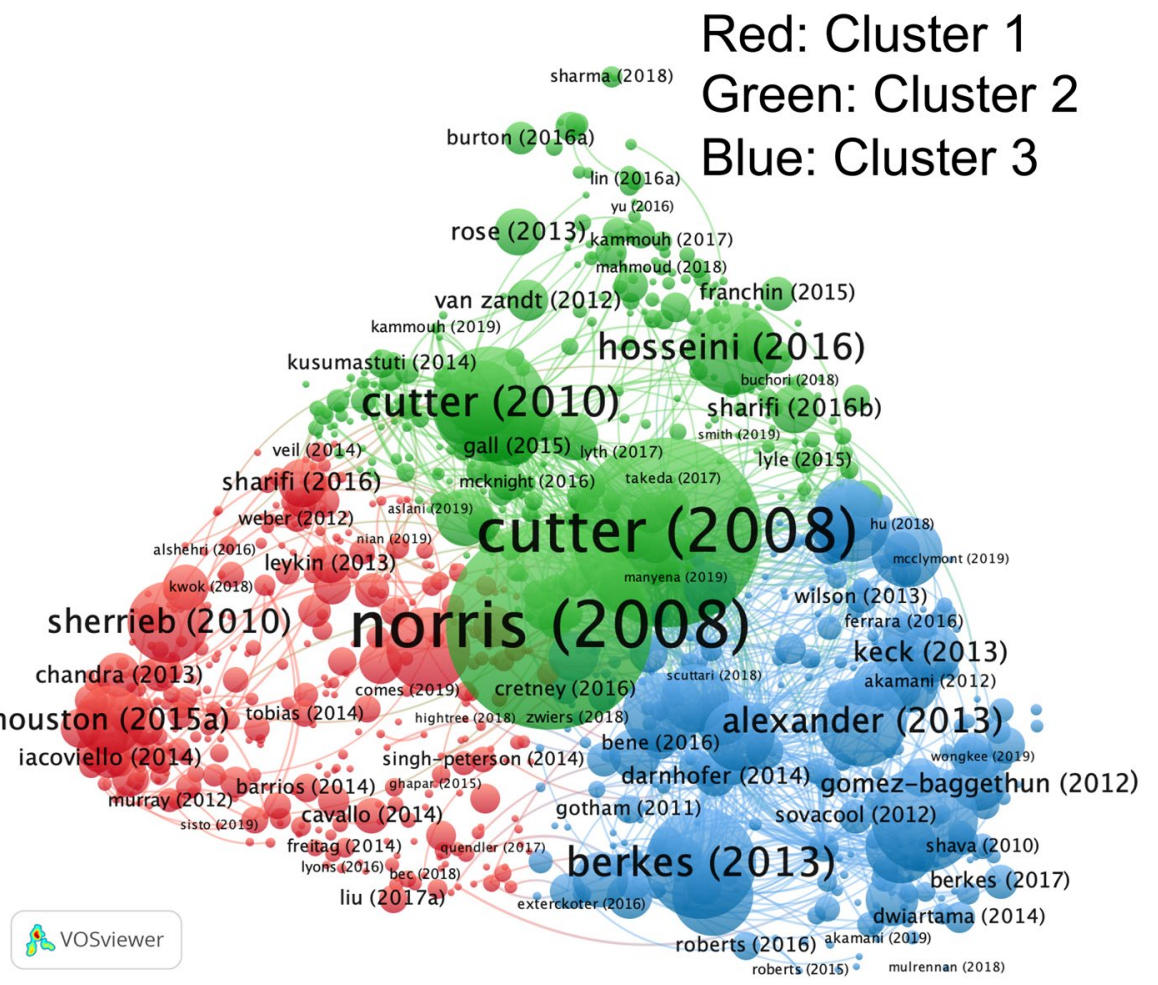

Fig. 4 Results of bibliographic coupling relations with clusters

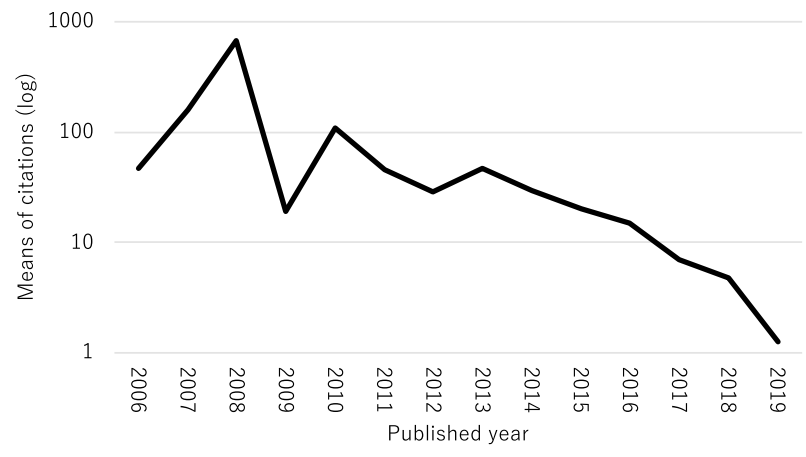

Fig. 5 Mean of citations of documents published annually

Alexander (2013) examined the historical development of the meaning and usage of the term resilience (not community resilience), which originated from resilire and resilio, Latin words for "bounce (back)." This clearly depicted how academic domains adopted the term resilience within the time frame. Alexander's (2013) schematic diagram of the term's evolution shows that its origins can be traced 


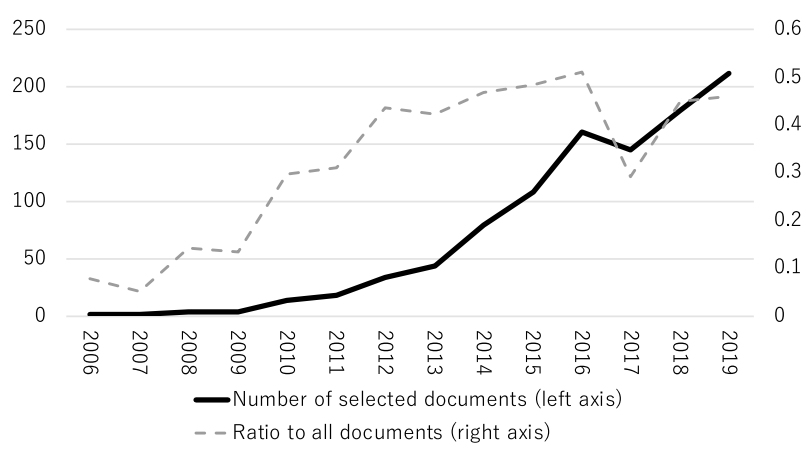

Fig. 6 Number of documents in dataset B and their ratios to all documents

back to AD 35 and reached psychology in the 1950s. Furthermore, regardless of developments in psychology, resilience became popular among the social sciences in the late 1990s when community resilience was mainly discussed, which consists of disaster risk reduction, climate-change adaptation, and others. For psychology and the social sciences, Berkes and Ross (2013), the most influential in this cluster, provided an integrated approach to community resilience based on two strands of literature on community resilience: the psychology of development and mental health and social-ecological systems. While health and psychology focus on individuals' ability to recover from adversity, social-ecological systems view resilience as the capacity to continually change and adapt and yet remain within critical thresholds. Moreover, the former focuses on the outcome for the individual; whereas, the latter is fundamentally interested in the systems (rather than its components) and its dynamics.

Other documents considered the concept of resilience as a bridge between the natural and social sciences. Welsh (2014) argued that resilience theories originate from two distinct epistemological communities (natural and social science) in its mobilization as a boundary object. This study argued for a critical interrogation of pluralistic resilience theories and reflected on their emancipatory capabilities. Olsson et al. (2015) also maintained that resilience is often promoted as a boundary concept to integrate the social and natural dimensions of sustainability. However, this creates a troublesome dialog from which social scientists may feel detached. Hence, the study asserted that incommensurability and unification are roadblocks to interdisciplinary dialog; whereas, pluralism that draws on core social scientific concepts would better facilitate integrated sustainability research. The ambiguity of the meaning of resilience has also been supported by Alexander (2013).

More documents have also focused on how more specific academic domains are linked as a function of the community resilience concept. Brown and Westaway (2011) synthesized knowledge on agency, capacity, and resilience across human development, well-being, and disaster literature to provide insights into supporting more integrated and human-centered approaches to understanding environmental change. Brown and Westaway (2011) understood agency as "the capacity of individuals to act independently to make their own free choices" (p. 322); whereas, 


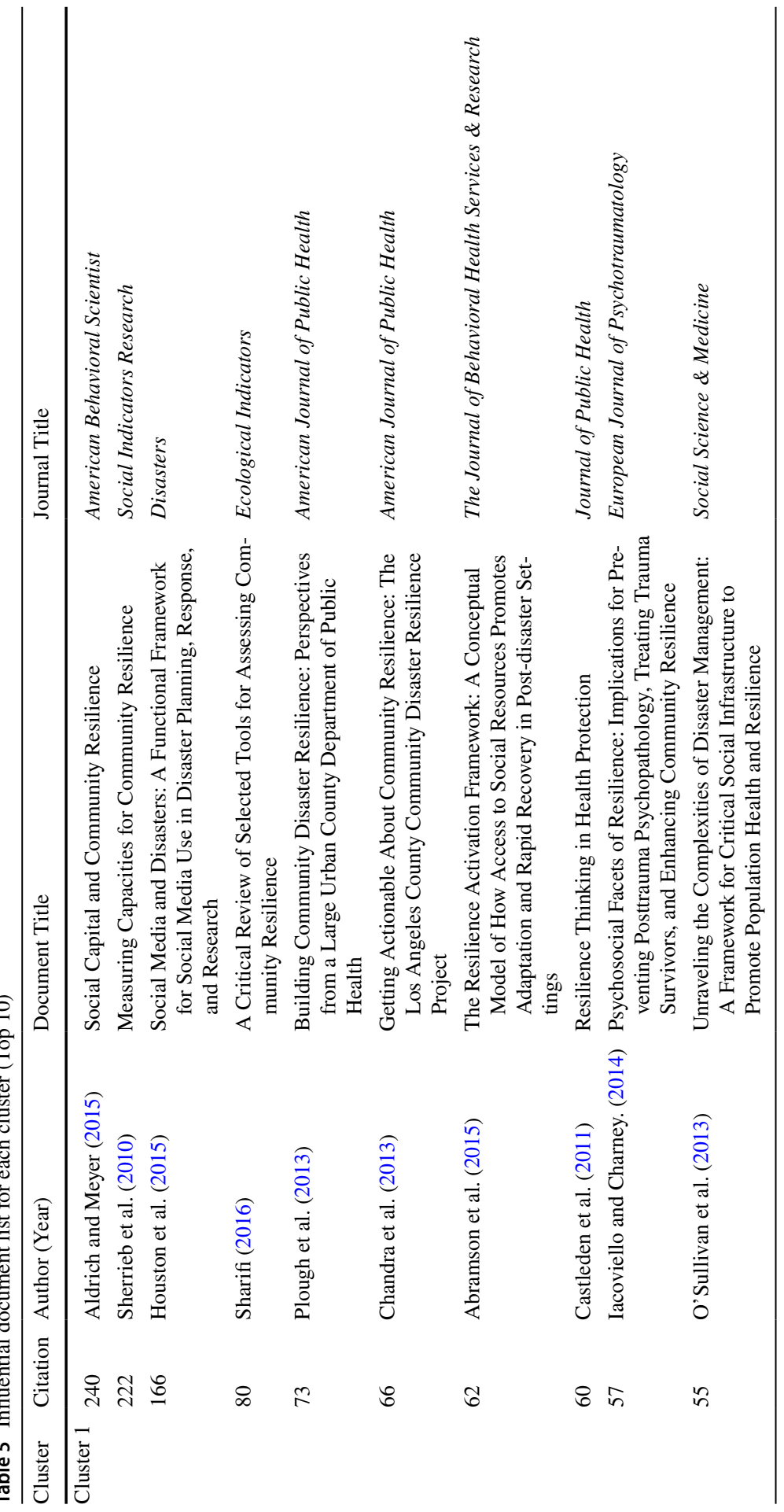




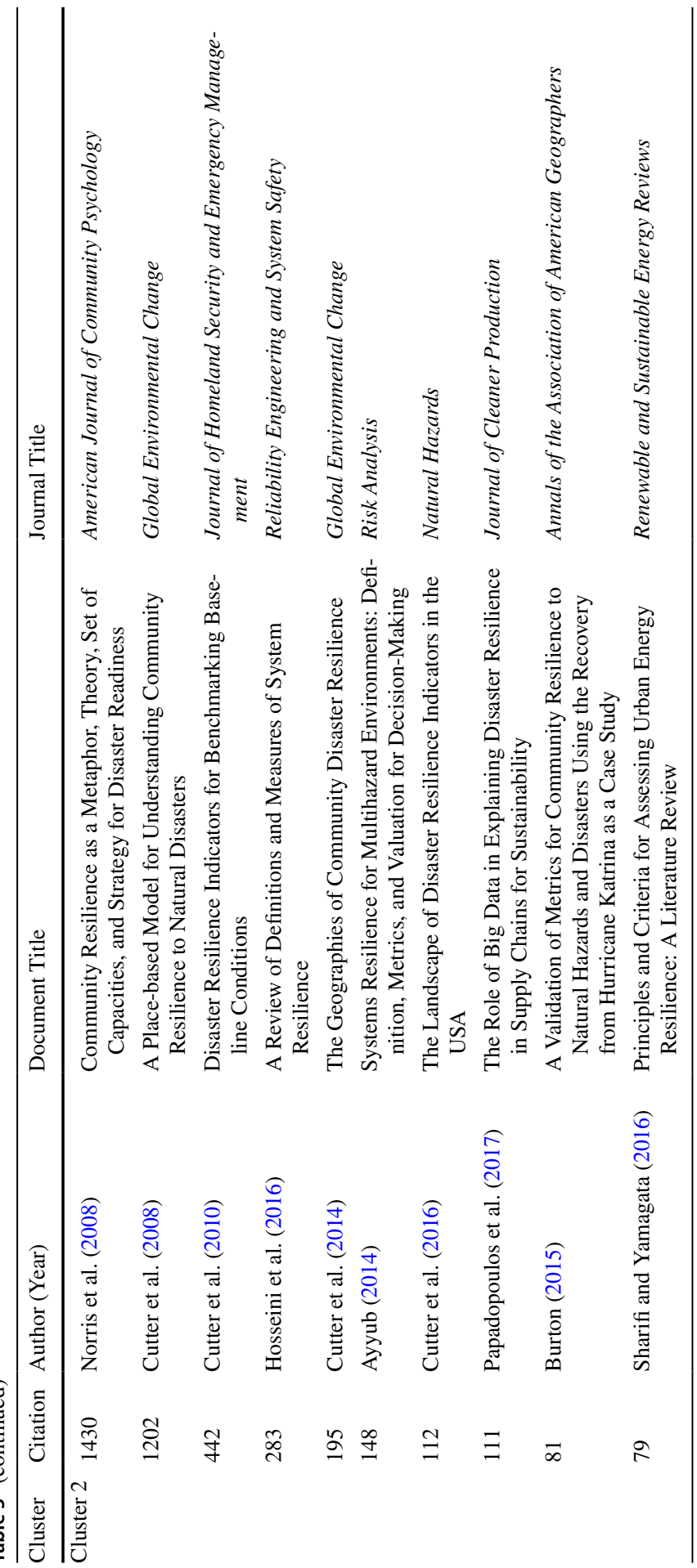




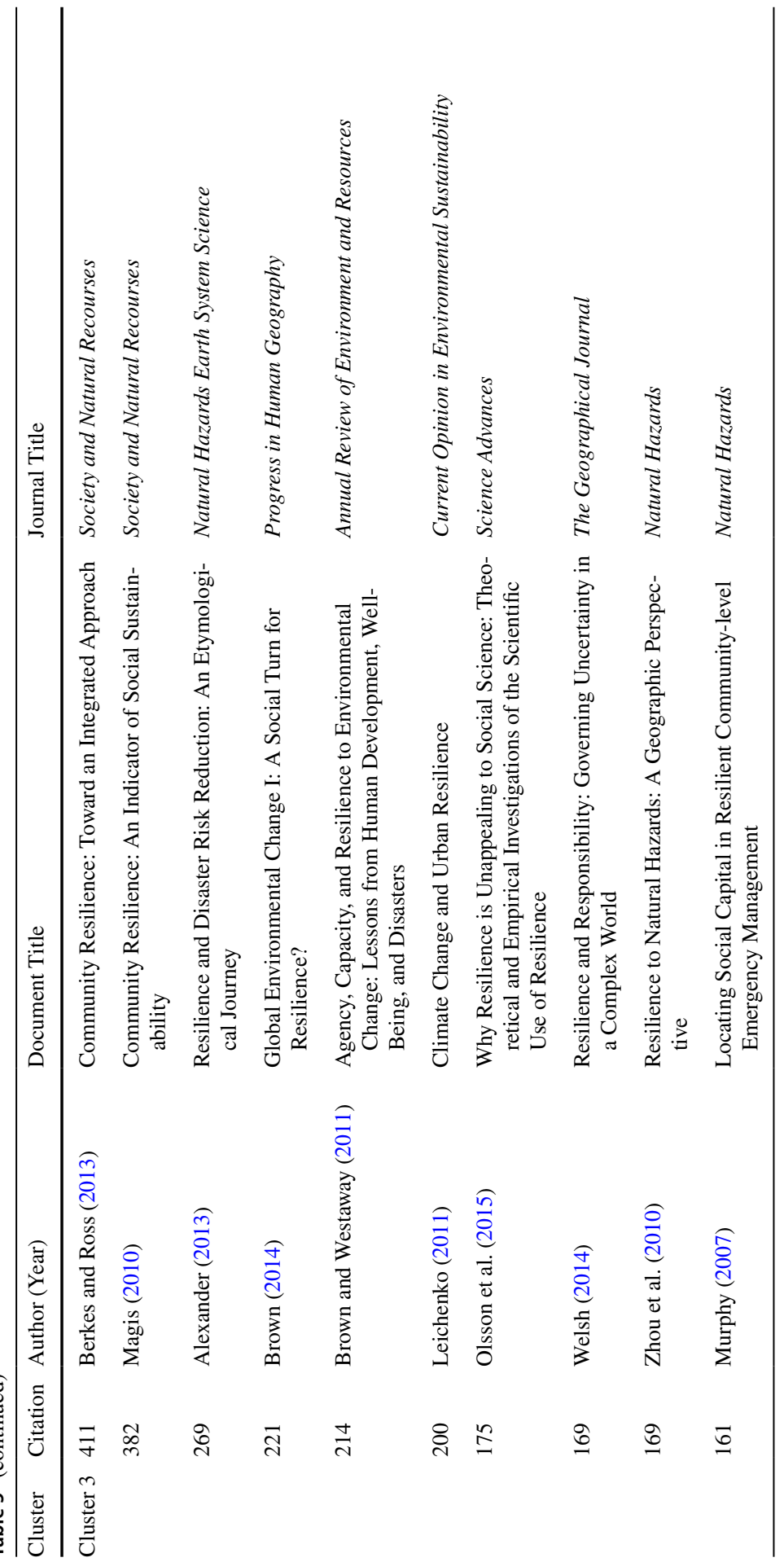


capacity is "the ability to generate an outcome or perform a task and also to learn, and the potential for growth and development" (p. 322). Brown (2014) further examined whether and how resilience theory and applications incorporate social and political dimensions, reviewing theoretical and empirical published research across geography, environmental change, natural resource management, and international development, concentrating on new work since 2010. Leichenko's (2011) review recognized the growing ubiquity of the term resilience within the literature on climate change and cities and, focusing on urban resilience, argued that to ensure the term retains its utility, one must continually question how it is used and applied to urban areas.

Cluster 3 views (community) resilience as a good example of a bridge between scientific and academic domains owing to the ambiguity of its conceptualization. However, this makes it difficult for researchers to trace discussions around community resilience; therefore, a synthesis through document survey is essential for academic progress.

\subsubsection{Cluster 2: constructing models and indicators of community resilience}

Cluster 2 (green) contains 308 documents, including eight in category one and 91 in category two. The top influential documents in this cluster are also the most prominent ones in the entirety of community resilience articles. This cluster mainly discusses modeling and assessment indicators, with some documents comparing different assessment methodologies while others comprehensively or partly evaluating community resilience. Moreover, some studies discussed the resilience of other systems, such as energy resilience, which is associated with community resilience models.

Norris et al. (2008), the most influential document in both the whole map and this cluster, presented a community resilience theory that covers contemporary understandings of stress, adaptation, wellness, and resource dynamics. Although this theory is primarily based on disaster-related health or community members' mental health problems, previous conceptualizations of the theory have been integrated in different ways. Therefore, the discussion in this document can apply to other domains as well. Community resilience was defined as a process linking a network of adaptive capacities (resources with dynamic attributes) to adaptation after a disturbance or adversity. This covers the discussion on resilience from a summary of its definitions to its destructuring toward networked resources. The network resources here refer to economic development, social capital, information and communication, and community competence. This is a working definition that can be used for application, and the document analysis will later adopt it. However, Norris defined community resilience as a process while Sherrieb et al. (2010) pointed out that Norris et al.'s (2008) former two network resources can have structural characteristics while the latter two are process-oriented.

Some documents were reviews related to community resilience modeling. Hosseini et al. (2016) examined recent (2000-2015) research articles focusing on defining resilience and classified the literature in terms of resilience modeling and planning. In addition, Cutter et al. (2016) analyzed the existing qualitative and 
quantitative approaches to resilience assessment to delineate common concepts and variables. The most common elements in all assessment approaches can be divided into attributes and assets (economic, social, environmental, infrastructure) and capacities (social capital, community functions, connectivity, and planning), which the document analysis also adopted later in the paper.

Cutter et al. (2008), one of the most influential scholars, provided a novel community resilience framework - the disaster resilience of place (DROP) modeldesigned to improve the comparative assessments of community-level disaster resilience. Here, community resilience is classified into two, inherent and adaptive, with the former composed of community competence and ecological, social, economic, institutional, and infrastructure resilience. In this model, inherent resilience refers to the qualities of a community while adaptive resilience pertains to a community's capacity [this was explicitly mentioned in Cutter et al. (2014), which applied part of this model to real-world cases]. Cutter et al. (2010) used the DROP model to measure the inherent resilience of 736 counties in the southeastern United States. Furthermore, Cutter et al. (2014) created an empirically based metric called the Baseline Resilience Indicators for Communities (BRIC), which is both conceptually and theoretically sound and easy enough to use in a policy context, which consists of social resilience, economic resilience, community capital, institutional resilience, housing/infrastructural resilience, and environmental resilience. Cutter's series of studies persistently and deductively defined indices of community (inherent) resilience and quantitatively assessed it by applying it to United States counties. Cutter et al. (2014) maintained that despite the absence of critical threshold values of high or low inherent resilience, communities (counties) can compare their values with those of other places or with their own previous values. However, besides the endogenous problems surrounding the DROP model, as these studies adopted deductive reasoning, whether community resilience really works against real shocks needs to be checked and validated.

Meanwhile, Burton (2015) provided an externally validated set of resilience metrics at the subcounty level of geography. These identified the social, economic, institutional, infrastructural, community-based, and environmental dimensions of resilience, and the validity of the metrics was addressed via real-world case studies involving Hurricane Katrina and the recovery of the Mississippi Gulf Coast in the United States.

Concurrently, other articles discussed community resilience along with other concepts. Ayyub (2014) defined resilience in terms of its clear associations with the metrics of relevant abstract notions such as reliability and risk. Their study provided valuation methods and a cost-benefit analysis based on concepts from risk analysis and management. Papadopoulos et al. (2017) proposed and tested a theoretical framework to explain resilience in supply chain networks for sustainability using unstructured big data. Their study included community resilience as a part of their framework and referred to it as the extent to which social and economic resilience can be built within a supply chain network. Moreover, Sharifi et al. (2016) examined research related to energy resilience to develop a conceptual framework for evaluating urban energy resilience. While their paper did not mention the term community resilience, community remains an important player in urban energy resilience. 
Table 6 Major elements of community resilience

\begin{tabular}{|c|c|c|c|c|}
\hline & & $\begin{array}{l}\text { Norris et al. } \\
(2008)\end{array}$ & \multicolumn{2}{|c|}{ Cutter et al. (2016) } \\
\hline $\begin{array}{l}\text { Description } \\
\text { of } \\
\text { community } \\
\text { resilience } \\
\text { elements }\end{array}$ & & $\begin{array}{c}\text { A set of } \\
\text { networked } \\
\text { adaptive } \\
\text { capacities of } \\
\text { resources which } \\
\text { should be robust, } \\
\text { redundant, or } \\
\text { rapidly } \\
\text { accessible }\end{array}$ & $\begin{array}{l}\text { Attributes and } \\
\text { assets }\end{array}$ & Capacities \\
\hline \multirow{6}{*}{ Elements } & Economic & $\begin{array}{l}\text { economic } \\
\text { development }\end{array}$ & economic & \\
\hline & Social & social capital & social & $\begin{array}{l}\text { social capital } \\
\text { connectivity }\end{array}$ \\
\hline & Information & $\begin{array}{l}\text { information and } \\
\text { communication }\end{array}$ & & \\
\hline & Competence & $\begin{array}{l}\text { community } \\
\text { competence }\end{array}$ & & $\begin{array}{l}\text { community functions } \\
\text { planning (decision-making) }\end{array}$ \\
\hline & Natural & & environmental & \\
\hline & Spatial & & infrastructure & planning (spatial) \\
\hline
\end{tabular}

Gray cells mean not indicated.

From these articles on models and indicators, two pathways may be observed regarding the approach to community resilience: building community resilience as a process (capacity building, quality, etc.) and ameliorating indicators (proxies) that are closely associated with community resilience as an outcome (characteristics, etc.) including measurable processes. The former was identified by Norris et al. (2008), which focuses on the psychological domain and serves as the most influential document on community resilience among other domains. The study found that community resilience emerges from a set of networked adaptive capacities of resources-economic development, social capital, information and communication, and community competence-which should be robust, redundant, or rapidly accessible. For the latter pathway, Cutter et al. (2016), who reviewed community resilience indicators, stated that the most common elements can be divided into attributes and assets (economic, social, environmental, and infrastructure) and capacities (social capital, community functions, connectivity, and planning). Table 6 summarizes these essential elements of community resilience. Other documents, although discussing the same topics, relied on the influential articles as a starting point to construct frameworks for the survey.

\subsubsection{Cluster 1: applying community resilience to practice}

Cluster 1 (red) contains 397 documents, including three in category one and 113 in category two. This cluster mainly focuses on contributions to the application of community resilience in case study areas. The following briefly summarizes this cluster, referring mainly to the top 10 influential documents.

The salience in this cluster pertains to its focus on social aspects. The most influential document in this cluster is Aldrich and Meyer (2015), which challenged governmental organizations to spend heavily on difficult measures despite evidence that 
social infrastructure drives resilience. Highlighting the critical role of social capital and networks in disaster survival and recovery, this article provided policy recommendations for decision-makers. Abramson et al. (2015) proposed the Resilience Activation Framework to test how access to social resources, such as formal and informal social support, promotes positive adaptation or reduces psychopathology among individuals and communities exposed to collective disaster-related stressors. Iacoviello and Charney (2014) discussed a constellation of cognitive, behavioral, and existential factors that have been identified as contributors to resilience in response to stress or trauma. O'Sullivan et al. (2013) unraveled the complexities of disaster management to recognize the interdependencies between healthcare and broader social systems and how they intersect to promote health and resilience. This document built a framework for critical social infrastructure and developed a model to identify potential points of intervention to promote population health and resilience. Moreover, focusing on newly invented social media, Houston et al. (2015) comprehensively reviewed online, official, and scientific literature from 2012 to 2013 to develop a disaster social media framework with its own contributions to disaster management as opposed to traditional mass media.

Other documents evaluate community resilience while emphasizing social capital. Sherrieb et al. (2010) measured sets of adaptive capacities for economic development and social capital, two of Norris et al.'s (2008) networked resources for community resilience. Using publicly accessible population indicators, they measured the capacities of 82 counties in the state of Mississippi in the United States.

Some documents introduced the importance of community resilience in policies. Plough et al. (2013) examined why national policy across multiple federal agencies has identified building community resilience as a key component and discussed the core principles of community resilience theory in the United States. Abramson et al. (2014) explained how several governmental agencies have proposed enhancing citizens' resilience to prepare populations before disasters occur and as a counterbalance to social and individual vulnerabilities. Moreover, Castleden et al.'s (2011) review identified key concepts and explored the relevance of resilience when planning for disasters and protecting public health. Finally, Chandara et al. (2013) conducted a baseline survey that documents barriers to community resilience building and facilitators among the staff of health departments and community-based organizations.

The above review shows that this cluster is mainly examined to achieve this paper's objectives. Although influential documents highlight social aspects and/or entities engaged in building community resilience, other documents address different community resilience-related issues.

\subsection{General analytical framework for community resilience studies}

The analyses above show identical main targets for discussing community resilience according to keyword co-occurrence and its connections beyond academic domains through bibliographical network. Moreover, the latter analysis argues that while several documents have examined community resilience from the viewpoints 
Table 7 General analytical framework for community resilience studies

\begin{tabular}{llll}
\hline Main target (keyword) & Main focus (citation) & \\
\cline { 2 - 4 } & $\begin{array}{l}\text { 1. Applying com- } \\
\text { munity resilience to } \\
\text { practice }\end{array}$ & $\begin{array}{l}\text { 2. Constructing models and } \\
\text { indicators of community } \\
\text { resilience }\end{array}$ & $\begin{array}{l}\text { 3.Conceptual- } \\
\text { izing community } \\
\text { resilience }\end{array}$ \\
\hline $\begin{array}{l}\text { A. Societal systems } \\
\text { B. Psychological domain }\end{array}$ & & \\
C. Social-ecological systems & & \\
\hline
\end{tabular}

of modeling and indicators (cluster 2) and conceptualization (Cluster 3), it is evident that approaches to community resilience have remained scattered and unsynthesized. This fact adds value to this paper, whose aim is to survey documents on community resilience approaches.

Worth noting is that bibliographical networks (citations) somewhat reflect academic domains, but as seen above, documents in each cluster share the same focus, which is different from that of academic domains. Therefore, both keyword and citation clusters can be two axes of the framework to review community resilience studies despite not being perfectly independent of each other. This provides a general analytical framework for community resilience research, which contains nine realms consisting of three academic targets and three main emphases as shown in Table 7.

\section{Major approaches to community resilience on societal systems}

This chapter describes the document survey results mainly with dataset B based on the abovementioned framework but focusing on the realm of 1. Applying Community Resilience to Practice and A. Societal Systems. I included some important and influential documents that were excluded from data B in the survey to provide supplementary explanation. For descriptive insights, I focused on four analytical viewpoints: stability, recovery, adaptability, and transformability, if applicable, as some documents did not explicitly discuss these viewpoints and did not differentiate, for instance, between recovery and transformability and between adaptability and transformability. Furthermore, unless it was necessary to do so, I did not identify differences between processes and outcomes for community resilience because processes are eventually measurable outcomes in practice (Cutter et al. 2016). The concept of resilience includes dynamic systems that contain feedback systems in order to allow processes to be analyzed as measurable outcomes (refer to 1.1 of this paper).

Before conducting the survey, I took note of two things. First, I determined the academic domains of documents through their keywords based on their abstracts and, if necessary, full-text contents. In addition, as stated above, some documents might be cited and categorized in Cluster 2 while their primary focus could be closer to Cluster 1 . Therefore, although the framework shows an overview of academic 
studies on community resilience, I checked the documents in all clusters and recategorized them manually in their appropriate main focus clusters for documents in categories A and B and, if necessary, $\mathrm{C}$.

Second, in surveying the documents, I excluded those that do not focus on community resilience (such as household resilience ${ }^{2}$ ); those that assess community resilience in a general sense or merely evaluate specific projects related to it; ${ }^{3}$ those that provide indicators, models, or concepts of community resilience (I considered them in clusters 2 and $3^{4}$ ); those that emphasize a small aspect of community resilience such as earthquake evacuation; and those that seem largely unrelated to the main flow of the discussion below.

\subsection{Achievements in community resilience on societal systems}

The influential documents defined the following major elements of community resilience: economic, social, information, competence, natural, and spatial. Community resilience is a process to explore these aspects or their outcomes (capacities, resources) promoting robustness, redundancy, resourcefulness, and rapidity or rapid accessibility (4 s) (Bruneau et al. 2003). However, many documents focus on only one aspect or several. Therefore, this section explains achievements based on these elements alongside other topics identified by the document survey, starting from the most discussed element.

\subsubsection{Social element}

a. Bonding and bridging social capital

Several documents in the survey highlighted social capital and discussed it as a contributing factor to community resilience or its proxy indicators. The concept of social capital, while ambiguous, encompasses different views and "can be regarded as a collective asset in the form of social relations, shared norms, and trust that facilitate cooperation and collective action for mutual benefits" (Bhandari and Yasunobu 2009, p. 491). Moreover, in terms of its network scopes, social capital can be classified into three: bonding, bridging, and linking. "Bonding social capital refers to relationships among members of a network who are similar in some form... [b] ridging social capital refers to relationships among people who are dissimilar in a demonstrable fashion, such as age, socio-economic status, race/ethnicity and education... [1]inking social capital is the extent to which individuals build relationships with institutions and individuals who have relative power over them" (Hawkins and Maurer 2010, p.1779-1780).

\footnotetext{
${ }^{2}$ Examples are Chaney et al. (2013), Sadri et al. (2018), and others.

${ }^{3}$ Some documents evaluated community resilience projects such as D'agostino et al. (2011), Bulley (2013), Wells et al. (2013), Fois and Forino (2014), Akamani, Wilson et al. (2015), and Ahmed et al. (2016), to point a few.

${ }^{4}$ One example is Magis (2010), one of the most influential documents, which is not discussed in this paper.
} 
Particularly important within communities, as Murphy (2007) put it, are social capital resources both in community groups (bonding) and between these groups (bridging) and local municipal authorities (linking), which may work toward improving community resilience against risks and hazards, which, according to case studies, include electric power blackouts and water-borne disasters. In terms of function, social capital is associated with stability or recovery. If a document discusses enhancements or alterations to social capital, with its direct link to social structure, transformability is one of its main viewpoints. Documents in this subsection discuss bonding and bridging social capital, and the following subsection deals with linking social capital.

Community resilience as a process in normal circumstances As a process in normal situations, community resilience is studied not only in terms of social interaction but also in terms of intervention projects that can build it. Without using the term (community) resilience, a large number of documents highlighted the importance of mobilizing local social resources for community-based disaster preparedness, mitigation, response, and recovery.

Social capital for enhancing community resilience Defining resilience as a dynamic social process partly determined by communities' ability to act collectively and solve common problems, Smith et al. (2012) developed a framework in which various social interaction patterns define the community resilience process with emphasis on how communities adapt and respond to dynamic environmental conditions. Through case studies of forest-dependent communities within Southern Appalachia, the study found that different community resilience processes can take place in communities with similar levels of resource dependence; such processes are defined by a community's composition of internal social ties and cross-scale linkages to external agencies and organizations.

Finkbeiner (2015), focusing on small-scale fishing communities in Mexico, evaluated fishing cooperative characteristics and environmental conditions as possible predictors of cooperatives' relative ability to diversify. The study found that diversification was crucial for risk mitigation and income stabilization (stability); whereas, the cooperatives' ability to specialize during favorable conditions might significantly help alleviate poverty and accumulate wealth. Therefore, the flexibility to switch among fishing strategies given the changing environmental conditions is important for the target population's adaptive capacity.

Enhancing social capital for community resilience To recognize the importance of social capital and enhance it, some documents proposed several projects. Freitag et al. (2014) presented cases of local community intervention in Washington State in the United States, and found the importance of bonding social capital. An asset-based appreciative inquiry approach was adopted, starting with workshops in which stakeholders identified built, natural, and social assets that strengthen human well-being (HWB) and then introduced earthquake scenarios that affect HWB. Then the participants identified assets that could facilitate adaptation to changed circumstances (a new normal) and discussed how such assets would achieve comprehensive community planning, hazard mitigation, and disaster recovery goals. Finally, neighborhood-scale social organization 
emerged as an important priority. This document deals with the transformability of community resilience, which is exemplified by the new normal.

Community resilience as a process during disaster recovery This section discusses the critical role of bonding social capital in the post-disaster phase as well as its possible negative effects on some people such as the marginalized. In addition, establishing social networks and systematic communication on normal days as practiced in time banking, for instance, will play a significant role in disaster recovery. The negative side of community resilience will then be described here.

Social capital as double-edged sword According to Aldrich and Meyer (2015), community resilience is the collective ability of a neighborhood or geographical area to cope with stressors and cooperate with one another to efficiently resume daily life activities after disasters and other critical events. This is called recovery. The study presented empirical evidence of how social capital, as a resource, strongly influences community resilience. The findings showed that social capital positively contributes to disaster resilience by encouraging resistance against different disaster recovery needs; in the case of Hurricane Katrina, for example, neighborhoods with higher voter turnouts before the storm were more successful at rejecting the placement of temporary trailer housing. However, the study also highlighted the potential drawbacks of social capital, especially bonding social capital, such as the assumption of control over the aid distribution process, which excludes the marginalized.

Regarding such disadvantages, Wickes et al. (2015) maintained that while social capital may reduce local community problems under normal conditions (stability), its effect may be limited in alleviating community distress in a post-disaster environment (recovery). In addition, community disadvantages, the concentration of vulnerable and ethnically diverse groups, and high-level residential mobility in the pre-disaster environment prevent communities from recovering after a disaster. In contrast, a neighborhood's structural conditions before floods have lasting and negative effects on community problems.

Time banking for community resilience As part of social capital, time banking is also studied as a contributor to community resilience. Ozanne and Ozanne's (2016) case study in New Zealand explained how time banks facilitate dyadic exchanges, meet members' practical needs, and build diverse skills. The study aimed to determine the broad capabilities developed in the time bank economy and demonstrate how these are mobilized following a series of earthquakes, facilitating community resilience. The study found that time banks gradually built a robust communication and social network that encouraged members to solve diverse practical problems facing the community. Moreover, the network fostered a strong sense of community-based on reciprocity and egalitarian values. Despite being created as a marketplace for local services, it galvanized adaptive capacities, eventually building community resilience during disaster relief and reconstruction. From these viewpoints, time banks could facilitate stability (in normal conditions), recovery, adaptability, and potentially transformability, as adopting time banks requires social structural change. Cretney et al. (2016) obtained the same findings using the same case study area.

Community resilience as an outcome in normal conditions Cutter et al. (2016) considered (bonding) social capital as an element of community capital. The study 
employed a suite of spatial and statistical techniques using an established community resilience measure, the BRIC, which is based on proxy indicators (refer to Sect. 2.3.2). The study focused on explaining the discrepancy in resilience between U.S. urban and rural areas. It performed nonparametric rank analysis, analysis of variance, and logistic regression to describe the relations between rurality and disaster resilience in contrast to that in urban areas. The binary logistic regression results revealed notable distinctions in the driving factors or characteristics of resilience in rural America compared with those in metropolitan America. In urban areas, disaster resilience is primarily driven by economic capital; whereas, in rural areas, community capital is the most important guiding factor of resilience. Rural areas, especially at the county level, have considerable spatial variability in disaster resilience components, suggesting that resilience enhancement cannot be realized via a one-size-fits-most strategy. Nevertheless, because the study adopted proxy indicators for community resilience, its viewpoints are unclear.

Usamah et al. (2014), in a study of two local communities with informal land tenures in a rural province in the Philippines, found that the community's social domains support their strong perceptions of resilience against the impacts of disasters. The study focused on the community's preparedness in responding to potential natural hazards that may turn into disasters for the surrounding community, which is regarded as outcome and stability. The residents have inbuilt resilience resulting from their view of disasters as part of life, strong social bonds, and governmental awareness of the validity of informal settlements.

Baek et al. (2015) proposed a sociotechnical framework for the design of collaborative services to foster community resilience in a farmers' market in Milan, Italy, which is viewed as transformability. The study found that the design of technical systems could strengthen social systems' resilience if the systems' state can be understood and concrete design problems identified. The framework revealed community resilience-related problems in the form of social network characteristics, which can be addressed by design interventions such as service strategies for human relations or resource management.

Community resilience as an outcome during disaster recovery One of the features here is that the documents measured community resilience based on respondents' subjective evaluation. The first two documents assessed community resilience according to respondents' perceptions while the last study discussed it qualitatively. Despite the recovery period being an indicator of community resilience, setting one recovery point for community life is debatable because residents have varying opinions on the feeling of recovery. Because community resilience is connected with recovery periods, these documents consider community resilience as an outcome.

Bonding social capital for recovery Townshend et al. (2015) focused on the role of disaster resilience and capacity building in community recovery (however, I regard this focus as an outcome of a measurable process). This study was based on a potentially important link between place-based social cohesion and resilience and used Buckner's Index of Cohesion and the Index of Perceived Community Resilience. Perceived community resilience consists of respondents' subjective evaluation of social aspects, which might constitute general resilience. The study compared the cohesion and resilience indices of four Canadian rural communities, 
which have potentially different phases of coping and resilience and which experienced disasters and evacuation, finding a consistent significant positive correlation between cohesion and resilience despite variations in the strength of relationships.

Cagney et al. (2016), based on the finding that less attention paid to the social infrastructure may affect a community's rebuilding capacity, examined perceptions of preparedness and recovery (markers of community-level resilience could be regarded as stability and recovery) in the wake of Superstorm Sandy with a novel dataset that included a multimode survey of 12 severely affected neighborhoods. According to the findings, social resources (defined as higher social cohesion, informal social control, and social exchange) tended to affect recovery perceptions more in communities less affected by the storm. Moreover, the study suggested the potential value of different social interventions to better equip communities on disaster response.

Madsen and O'Mullan (2016) reported a qualitative participatory action study in a small rural Australian town that has suffered from a series of flood events. The study conceptualized community resilience as communities learning to adapt (adaptability) and transform (transformability) in response to life's uncertainties and concluded that social capital is crucial to community resilience, and while resilience is tested only during adversity, social capital needs to be developed well before natural disasters occur.

b. Linking social capital

This subsection deals with linking social capital, which can be referred to as relations with public entities such as governments and public libraries in the context of community resilience approaches. Like documents on bonding and bridging social capital, studies on linking social capital also discuss transformability in terms of changing social structures and reorganizing responsibilities.

Relations between the community resilience process and governments on normal conditions In relation to community resilience as a process, Wilson (2013b) discussed the complex interconnections between community resilience and policy corridors. Policy corridors refers to "macro-scalar exogenous processes and pathways that shape human decision-making at multiple scales that influence environmental and societal transitions" (Wilson 2013b, p. 299). The study stated that although building strong community resilience is often an endogenous process linked to local customs, community-level actors cannot always be left on their own to forge their resilience pathways without state interference. Resilience transitions need some external regulations, and in most cases, the state has to play at least some role in guiding and influencing the shift toward strong community resilience; that is, resilience is not made and does not emerge out of a vacuum but is rather transferred through complex processes of policy and other exchanges between communities and wider society. Therefore, the study proposed that the state and communities establish a new contract, as new forms of institutionalization, regulation, and spatialization become significant in the uneven development of resilience spaces. Despite focusing on the nation-state, the study's argument may also apply to other external factors such as municipalities. Such a discussion is highly associated with transformability. 
Relations among these actors are essential for community resilience, but certain challenges to effective cooperation remain. According to Singh-Peterson et al. (2015), emergency management in Australia has recently transitioned from a command-and-control civil defense structure to one that promotes shared responsibility between governments, businesses, nongovernment entities, communities, and individuals. Governments are still seen as largely responsible for the case study's disaster resilience; however, local community groups consisting of volunteers are also deemed generally liable for disaster resilience despite their obvious limitations in capacity and resources, which are important for building community resilience. This views transformability as the revision of responsibility that requires change within a community's social systems.

Stakeholder participation is also considered pivotal for building resilience, with stakeholders actively involved in the process. Conducting a case study of the Natural Disaster Resilience Program in Queensland, Australia, using social-interactive discourse theory, Aldunce et al. (2016) found critical aspects that require urgent attention from stakeholders, especially the local government and the community, and challenged them to address meaningful communication and power structures, a process that is associated with transformability. Moreover, the study asserted the urgency of moving from experiential learning to social learning, which is categorized under the competence element. Other documents also discussed the important role of municipalities, such as Joerin et al. (2012), who examined a case in India.

Steiner (2016) focused on remote rural communities in Scotland with weak engagement history and explored whether community interventions can develop community resilience as an adaptive capacity. The study found that uniting people and opening communication channels among different community groups significantly influenced community resilience development, which could also be considered as transformability. Moreover, the study suggested that the process of developing community empowerment and resilience needs to be facilitated by external actors and relevant stakeholders.

Relations between the community resilience process and governments during disaster recovery Barrios (2014) reviewed the contributions of anthropological literature and the ethnographic case studies of two post-Hurricane Mitch housing reconstruction sites for theorizing community and resilience in post-disaster reconstruction. The study emphasized that the shapes and qualities of communities depend on their pre- and post-disaster relations with government agencies and aid organizations (transformability). Consequently, definitions of community resilience and disaster mitigation programs must consider the emergent and relational nature of communities to address the long-term causes and impacts of disasters.

Relations between community resilience as an outcome and governments on normal conditions Cohen et al. (2017) maintained the importance of information that municipal authorities provide to the population to develop or enhance resilience against emergencies (this discussion is related to the information element). The study assessed community resilience using the Conjoint Community Resilience Assessment Measure, an empirical, scientifically developed tool recognized as a valid community resilience measure administered via household sampling. This 
information is critically important for decision-makers and local leadership when developing resilience building policies and planning public communication.

Relations between community resilience as an outcome and governments during disaster recovery Jordan et al. (2016) extended community resilience and vulnerability theories by linking both pre- and post-disaster conditions to multisector recovery outcomes and analyzing the circumstances that led to infrastructural and social recovery in Indian villages affected by the 2004 Indian Ocean Tsunami. The study examined conditions affecting recovery and analyzed data using fuzzy-set qualitative comparative analysis. Multiple pathways to infrastructural and social recovery were found, all of which required good government resource accessibility and good recovery actor coordination.

The main discussion with respect to linking social capital was the roles and responsibilities of communities and governments in both pre- and post-disaster phases to reorganize the social structure for future disasters. Japan especially highlights the limitation of public help while asserting the importance of selfhelp and mutual help. Moreover, other nations also discuss the crucial role of mutual help. In addition, the roles of private sectors also attracted the interest of scholars and practitioners, as will be discussed later. However, a challenge here involves the vagueness of these roles and the trend of populations' continuous dependence on public help before, during, and after disasters. Differences among these roles and responsibilities would depend not only on hazard, exposure, vulnerability, and capacity in a community (related to the competence element below) but also on government policies. Exploring pathways toward the appropriate setting of roles and responsibilities is a challenging issue as well. This discussion is directly related to concepts of political economy, such as neoliberalism. The next topic, meanwhile, is closer to the relations between communities and governments but starts its focus on security issues.

Community resilience vs. governmentality for security and recovery Two documents discussed community resilience from the lens of community security. Coaffee and Fussey (2015), in an investigation of Birmingham in England, introduced security-driven resilience practices that conflicted with other policy priorities focusing on community-centered social cohesion, posing a series of questions on social control, surveillance, and the ability of national entities to foster community resilience in local areas despite the state's attempts to label the same spaces as dangerous. The study argued that the security-driven logics of resilience generate differences regarding how resilience is operationalized and produce and reproduce new hierarchical arrangements which may undermine some of the basic aspirations and principles of the resilience logic itself.

Meanwhile, Rogers (2013) identified three key forms of resilience: organizational, technological, and community. With emphasis on community resilience, the study showed that both positive and negative forms of governmentality are possible. The positive aligns well with progressive approaches to participatory governance while the negative, emerging from the prioritization of organizational and technological concerns, is consistent with state-centric and neoliberal tactics of crime control and citizen responsibility. 
This article examined the case of the UK riots in 2011 and analyzed the tension between positive and negative forms of resilience as governmentality.

In connection with this issue, Barrios (2017), which belongs to category three, tackled neoliberalism and disaster reconstruction. For brevity, the study referred to neoliberalism simply as "a cultural trend where policymakers, political leaders, and the public at large propose the subjection of all facets of human life to capitalist cost-benefit analysis as a mechanism for creating social well-being" (Barrios 2017, p .8). The study highlighted the tendency of neoliberalism to ignore the sentiments of disaster-affected populations and restructure relations between government and private sectors. For example, "In New Orleans, neoliberal visions of the city's possible future captivated the imagination of gentrifying resident constituencies, who became key allies of expert planning teams in legitimizing so-called participatory recovery plans" (Barrios 2017, p. 254). Nonetheless, the study insisted that affect and emotions remain critical dimensions of ways people experience catastrophes and articulate what it means to recover.

Potential roles of public libraries in building community resilience Public libraries are regarded as another important actor in community resilience. Despite focusing on their potential roles, two documents discussed how libraries can contribute to community resilience in normal circumstances and disaster recovery, referring to them as important resources gained from linking social capital.

Grace and Sen (2013) examined daily working practices to explore how public libraries both promote and inhibit community resilience. "Several areas of interest emerged: the existence of a split between the social worlds of the library worker and user, the role of technology in this split, the role of professionalism as discourse in rationalizing the use of certain technologies, the role of management in perpetuating this discourse, the place of outreach in bridging the gap between these social worlds, and the environment as an abiding concern" (Grace and Sen 2013, p. 513).

On the other hand, with regard to the disaster recovery phase, Veil and Bishop (2014) examined the role of public libraries in the community resource network. The Federal Emergency Management Agency in the United States designates public libraries as an essential community organization that plays a role in enhancing community resilience. The study's results showed several opportunities for libraries to do so, which include offering technology resources and assistance; providing spaces for offices, meetings, and community living areas; serving as a redundant communication channel and repository for community information and disaster narratives; and adapting or expanding existing services to meet the community's changing needs. However, as Veil and Bishop (2014) put it, libraries also face challenges in improving community resilience, such as the temptation to overcommit their capacity and staff capability beyond their mission and a lack of long-term disaster plans and collaboration with other public actors.

c. Summary: main issues regarding the social element

First, the above-mentioned documents consider bonding and bridging social capital as highly contributory to community resilience in all stability, recovery, adaptability, and transformability viewpoints. However, one obstacle involves overcoming or striking a balance regarding its negative aspects, such as group polarization. A similar statement could be said for linking social capital, in which the roles and 
responsibilities of communities and public entities (governments and public libraries) were discussed. One can easily say that cooperation among different groups is largely important because of their varying expectations of resources and synergistic effects. However, attempts to encourage populations to recognize such importance and hence achieve substantial cooperation remain in progress, which directly affects transformability, or changing social structures. Indeed, harmonizing different social capitals for community resilience is a challenging task.

As evident from communities' scarce capacities and resources (Singh-Peterson et al. 2015) and libraries' overcommitment (Veil and Bishop 2014), along with actors' expectations as demonstrated in Barrios (2017), studies need to discuss (1) which resilience should be built for whom (targets [this issue will be identified later as equitable resilience]); (2) who should do what to this end, which includes constructing social systems such as time banks (focusing on actors and goals); and (3) how to find decision pathways on these issues (planning [decision-making]).

\subsubsection{Information element}

The information element consists of both information and communication, which are closely interlinked with social capital and technologies. Communication is achieved through social capital, which involves sharing information including memories, while technology is used to disseminate and impart information and promote communication more efficiently. Moreover, they are important tools/methodologies for enhancing community competence such as capacities.

a. Social (collective) memory

One frequently discussed element here is social (collective) memory, which partly represents disaster subculture, where memories of disastrous experiences are shared. Social memory is a contributing factor to community resilience that sometimes has negative effects. In some cases, residents' experiences of small-scale flooding discouraged or hindered them from conducting a prompt evaluation of future largescale floods. In another example, Engel et al. (2014) suggested that if disaster subculture is directed at hurricanes, it would be unsuitable for large-scale flooding. Colten et al. (2012) referred to this memory as inherent resilience by presenting an example in which natural resource-dependent residents were deployed to cope with disruptions, which they then retained in their collective memory. As the memory is based on experience, which constitutes current societal structures, this tends to be inclined toward stability, recovery, and adaptability. However, with regard to using a certain community's memories so that other communities could build resilience from a transformability standpoint, this survey found no study that discusses this issue. Moreover, a certain process utilizes memories to make a community resilient; therefore, this element could be thought to adopt community resilience as a process.

The collection of cultural practices that have emerged in response to recurring disasters over time is identified as disaster subcultures. Engel et al. (2014) worked on an empirical appreciation of disaster subcultures in the Netherlands enabled by the value of the disaster subculture perspective and unveiled several elements surrounding the flood reality faced by neighboring parishes, which might otherwise have gone unnoticed and which appear central to understanding their vulnerability 
and resilience levels. The study's contention is that disaster subculture allows for a greater understanding of the cultural context from which vulnerability to and resilience against specific and recurrent threats emerge.

Meanwhile, social memory is another representation of disaster subculture. In a continuous discussion of social memory for community resilience pathways, Wilson (2013a) asserted that in disaster areas, such as Christchurch in New Zealand, where social memory was relatively poorly developed, the lack of learning processes before earthquakes complicates the implementation of positive learning pathways. Moreover, Wilson (2015) showed how a local community's inbuilt memory helps shape resilience pathways. This study focused on interconnections between social memory and community resilience, with emphasis on analyzing the importance of rites, traditions, and social learning processes in shaping community resilience and vulnerability. Wilson et al. (2017) further examined the complex interlinkages between social memory, community resilience, and land degradation and found that social memory is seen as an important rationale for a local community's ability to manage and cope with land degradation. The study highlighted the importance of the three components of social memory-rites, traditions, and social learning processes-which help shape community resilience against land degradation processes. It also found that the loss of social memory and learning pathways associated with managing land degradation is emerging as a critical factor that prevents stakeholders from effectively addressing land degradation issues.

In addition, McEwen et al. (2017) maintained that a conceptual contribution to global priorities is sustainable flood memory in the context of effective flood risk management. The study focused on the summer 2007 floods in the UK and aimed to clarify how flood memories provide the affected communities a platform for developing and sharing lay knowledge and creating social learning opportunities to increase their adaptive capacities for resilience. The study found an association between sustainable flood memories and relational ways of knowing situated in emotions, changing materiality, and community tensions. Given the concept's value and the importance of memory work, this document proposed a framework to translate the concept into practical community resilience initiatives and explain how communities share risk and flood experiences.

While these studies presented experiences that often produce knowledge or wisdom to be passed down to future generations, other documents focused on ecological knowledge. Gómez-Baggethun et al. (2012) showed how traditional ecological knowledge (TEK) and shared belief systems could facilitate collective responses to crises and help maintain the long-term resilience of social-ecological systems in villages in Spain. McMillen et al. (2017) studied rural communities in Hawaii in the United States and described the role of TEK in their adaptation to social-ecological change. While such indigenous knowledge may be lost as people adopt commercial agricultural practices and switch to nonagricultural livelihoods, which can be seen almost everywhere, Shava et al. (2010) demonstrated that residents can restore such knowledge when contingent opportunities arise. Targeting immigrant gardeners in New York in the United States and relocated farmers in Zimbabwe, the study showed how these communities draw upon their knowledge reserves to respond to changes in their local environments. Such knowledge could 
empower people to sustain their livelihoods and community well-being and thus adapt to environmental changes and displacement.

b. Information and communication promoted by technologies

Social media Social media is an effective, relatively new tool for disseminating information not only from official entities such as governments and mass media but also from general populations. One of its advantages is that it can spread smaller place-based information (e.g., neighborhood level) more widely than conventional mass media by any entity or individual. On the other hand, its misuse has become a challenge, as demagogues and misinformation can make already disastrous situations even more chaotic. Because it is a tool, it can affect all community resilience viewpoints depending on how it is used. Several documents have studied the functions of social media especially before, during, and after disasters, but only two were identical in this survey.

Houston et al. (2015) performed a comprehensive review of online, official, and scientific literature in 2012-2013 to develop a disaster social media framework. This would cover all activities before, during, and after a disaster and can be used to create disaster social media tools, formulate disaster social media implementation processes, and scientifically study disaster social media effects. Disaster social media users in the framework include communities, the government, individuals, organizations, and media outlets. It is implied here that they consider resilience as a process because social media promotes processes to reduce human losses, among others. Houston et al. (2015) listed the following functions of disaster social media:

1. providing and receiving disaster preparedness information;

2. providing and receiving disaster warnings;

3. signaling and detecting disasters;

4. sending and receiving requests for assistance;

5. informing others about one's own condition and location and learning the same about another disaster-affected individual;

6. documenting and learning what is happening in the disaster;

7. delivering and consuming news about the disaster;

8. providing and receiving disaster response information and enumerating ways to assist in the disaster response;

9. raising and developing awareness of an event, donating and receiving donations, and identifying and listing ways to help or volunteer;

10. providing and receiving disaster mental and behavioral health support;

11. expressing emotions, concerns, and well-wishes and memorializing those who have perished;

12. providing and receiving information about (and discussing) disaster response, recovery, and rebuilding, as well as telling and listening to disaster-related stories;

13. discussing the sociopolitical and scientific causes and implications of such events and identifying responsible individuals;

14. (re)connecting community members; and

15. implementing traditional crisis communication activities. 
Zou et al. (2018), in a case study of Hurricane Sandy, analyzed the spatial-temporal patterns of Twitter activities during the hurricane hit the northeast of the United States. According to the study, social media data could help improve post-disaster damage estimation but may also include other environmental and socioeconomic variables that influence the ability to mitigate damage. Such data could also provide valuable insights into strategies for utilizing social media information to improve resilience against disasters, which is related to recovery.

Digital technology in rural areas The roles of digital technologies in relation to community resilience have gained more attention in rural than urban areas, which generally dismisses the benefits of economic and technological development. Because digital technology is a tool, it can influence all community resilience viewpoints.

Focusing on the UK, Roberts et al. (2017) used a community resilience framework to critically examine the digital-rural policy agenda. The study deliberated various ways in which Internet-enabled technologies empower and disempower rural communities, leading to resilience and vulnerability. Here, community resilience is implied as an outcome. Finally, the study provided a holistic picture of the rural-digital agenda, highlighting gaps in implementation and understanding digital divide and inclusion.

Meanwhile, Roberts and Townsend (2016) developed an understanding of cultural and digital capital to evaluate how creative practitioners contribute to rural community resilience in Scotland. Specifically, through an in-depth qualitative analysis, the study described how broadband Internet access and online practices affect rural creative work and in turn enable creatives to participate in their rural communities at different levels, thus contributing to research into both rural community resilience and rural creative economies. Creatives are invested in their communities and rurality on several levels, facilitating community resilience through diverse ways of building cultural capital, with "ripple effects" from online activities. This study discussed community resilience in terms of quality (process).

Moreover, Ashmore et al. (2015) examined the relation between rural dwellers and Internet technology in the UK and sought to understand how it is altered with a significant increase in broadband speed. It argued for the use of resilience as a framework for researching such technological impacts, highlighting its potential usefulness in identifying alternative development narratives. Regarding community resilience, the study found that superfast broadband can facilitate the identification and development of control over everyday activities, which may shape individual empowerment and personal capacity building. It also found that the importance of speed lies in its association with reliability as well as the confidence that reliability can inspire regarding personal and business decisions, potentially enhancing resilience in uncertain economic times. Finally, the Internet is generally perceived as an individualized tool, with links primarily at the individual household and business scale, which can enhance individuals' social connectivity and perceived empowerment, as well as their skills and economic success. This document considered community resilience as a process.

c. Summary: main issues regarding the information element 
The primary discussions were on social (collective) memory, which includes traditional knowledge, social media, and digital technologies in rural areas, all of which entail benefits and detriments to community resilience. Since they are tools, all community resilience viewpoints could be related depending on how they are utilized. From the lens of the information element, Lloyd (2015) referred to information resilience as "the capacity to address the disruption and uncertainty, to employ information literacy practices to enable access to information relative to need, to construct new information landscapes, and to reestablish social networks" (p. 1033), which is closely related to community resilience. However, as previously discussed, information has occasional adverse effects on community resilience, which are not yet explored. The same is true for information resilience, which is associated with social capital and institutional resilience (explained in the next subsection).

\subsubsection{Competence element}

Although many documents emphasize the importance of the competence element to community resilience, which includes capacity building and decision-making, studies mainly focusing on approaches to this aspect are limited to those that use the keyword community resilience among the influential documents. However, as will be mentioned, some documents treat this element as one of their topics, such as Townshend et al. (2015), Ashmore et al. (2015), Palekiene et al. (2015), and Roberts et al. (2017) for capacity building; Wilson (2013b) and Wilson et al. (2016) for decision-making; and Aldunce et al. (2016) for competence. This element is also a part of institutional resilience and social resilience as addressed by Cutter et al. (2014). In the former term, institution pertains to the rules and norms governing human interaction, whether formal or informal (Herrfahrdt-Pähle and Pahl-Wostl 2012), and in community resilience, institutional resilience refers to that of a geographically based population or group (or a part thereof) from the neighborhood association to the county level. It is evaluated by the ratio of the population and its local disaster programs, such as in Cutter et al. (2014). The latter term, on the other hand, is "the ability of groups or communities to cope with external stresses and disturbances as a result of social, political and environmental change" (Adger 2000, p. 347) and is indexed by educational levels, among others, by Cutter et al. (2014).

Among these documents, Fischer and McKee (2017) focused on and analyzed rural community empowerment and resilience capacities in Scotland, which considers community resilience in terms of characteristics (outcome). The study analyzed the interaction among the community's organizational, infrastructural, and personal capacities, resulting in three major findings. First, a comprehensive understanding of a community's situation requires crucial interactions between capitals and capacities. Second, not only can capacities be at a low level; they can also be negative. Third, social capacities (arising from interindividual structures) act as powerful microstructures that restrict individuals' abilities to engage in community action. 
As mentioned above, the competence element is often discussed in association with other aspects or parts of other resilience types since it constitutes the very core of community, which must be the central actor for building resilience.

\subsubsection{Economic element}

a. Roles of the profit sector in community resilience

Several documents explored the role of profitable private sectors and discussed their connection with economic resources in local communities. Steiner and Atterton (2015), focusing on South Australia, studied the contribution of rural enterprises to economic, environmental, and social aspects of community resilience. The findings, emphasizing the economic aspect, revealed that rural businesses contributed to local resilience in both directly and indirectly. Direct contributions included the creation of local employment and local products and service delivery. Indirect contributions can be understood as the knock-on effect or the added value of primary business activities so that employment opportunities help reduce the risk of outmigration and depopulation. Rural business owners have the motivation and resources to respond to specific local challenges, opportunities, and characteristics and to proactively and skillfully turn them into entrepreneurial prospects. This could be also related to stability in the role of community resilience as an outcome.

Linnenluecke and Macknight (2017) sought to examine the conditions that motivate disaster entrepreneurship to contribute to community resilience. The study defined disaster entrepreneurship as the private sector's attempt to create or maintain value during and immediately after a natural disaster by taking advantage of business opportunities and providing goods and services that community stakeholders require. The study identified four approaches to disaster entrepreneurship: entrepreneurial business continuity, organizational response scaling by activating latent structures, improvising (for emergencies), and emergence (emergent behavior). The study also examined the association between each approach and community resilience, which is then related to the recovery aspect of community resilience as an outcome.

b. Contributions of the profit sector to community resilience

Kim and Marcouiller (2016) investigated the economic resilience of coastal regions in Florida against natural disasters using county-level panel data and found that coastal counties with stronger economies and better social conditions before the disaster experienced lower disaster losses. This document is under the stability viewpoint of community resilience as an outcome.

Tsai et al. (2016) described the relations between perceptions of tourism impact and of community resilience in areas with hazardous environments after natural disasters in Taiwan. The study found that stronger self-help and local adaptive capacities is a crucial component of a disaster prevention and response strategy. However, despite finding negative impacts of tourism, the study viewed tourism as a facilitator for speedy recovery because it can rebound fairly quickly upon the restoration of transportation and communication systems. Therefore, this document is considered to focus mainly on stability and recovery.

c. Summary: main issues regarding the economic element 
The common conclusion in these discussions is that the private sector, through its own roles, can contribute to community resilience mainly from stability and recovery viewpoints. The involvement of private firms in disaster preparedness, response, and recovery is emphasized in recent disaster experiences, after which practical activities are also conducted. However, several issues remain. First, with regard to the contributions of various actors and the clarification of their roles, this aspect may facilitate the adaptability and transformability of community resilience, which is related to the discussion on social capital. Second, regarding corporate social responsibility, it is important to connect academic discussions on business continuity plan/management (BCP/BCM) which include economic and community resilience. Several studies deal with how and in what aspects private firms could or should contribute to community resilience as a community actor and how this would be (economically) beneficial to them in return. However, despite some evidence of the economic impact of disasters (both negative in terms of damage and loss and positive in terms of recovery needs) and the contributions of the private sectors to disaster recovery, studies have yet to perform an economic evaluation of such contributions to community resilience.

\subsubsection{Spatial element}

The spatial aspect includes not only individual constructions but also spatial planning such as land-use planning, road networks, and others. These man-made objects have both positive and negative effects on community resilience.

a. Nonprofit firm management of critical infrastructure for community resilience

This aspect was found in only one document in dataset B. McKnight et al. (2016) examined the conceptual functions of nonprofit firms that manage a large proportion of critical infrastructures such as banking services, telecommunications, transportation, and utilities, on which community resilience depends. Community resilience research (here, resilience is considered as an outcome) has focused on the responses of public entities such as emergency services and government agencies and nongovernmental sectors whereas nonprofit firms are also engaged in responding to natural disasters. These studies use stakeholder theory to distinguish between firms adopting firm-centric postures (focused inwardly on firm outcomes) and those with community-centric postures (focused outwardly on stakeholders), with respect to natural disaster response, stating, for example, that "[f]irm-level resilience can stabilize a community by providing it with goods and services as well as maintaining employment in a time of crisis" (McKnight and Linnenluecke 2016, p. 301), which pertains to stability and recovery. These studies then theorized the relations between firmand community-centric postures and different community resilience outcomes.

b. Spatial planning

Studies on spatial planning cover a variety of fields. Saunders and Becker (2015) provided an overview of resilience and sustainability within land-use planning and natural hazards and discussed their interrelations. The study identified an issue surrounding the interchangeable use of the terms resilience planning and sustainable planning. It found that differences between resilience (regarded as a mostly shorterterm phenomenon) and sustainability (often related to longer-term aspirations) 
become most evident where disaster recovery is protracted. In this context, shortterm adaptations can lead to unsustainable practices in the long-term, which would necessitate a more strategic overview of resilience and sustainability. In the case of Christchurch, New Zealand, the study showed that a resilient community should also be a sustainable one to meet legislative requirements and ensure that the needs of future generations-economic, social, cultural, and environmental-are met. While resilience includes transformability, its adaptivity aspect gains more attention in practice.

Camps-Calvet et al. (2015) showed that bottom-up urban gardening initiatives in Barcelona in Spain in the form of land occupation and communalization represent forms of resistance that enhance social cohesion and collective action in challenging times. Specifically, this research examined how urban gardens help build community resilience and articulate forms of resistance and contestation against development pressure and commodified urban lifestyles. Moreover, the study provided mechanisms through which urban gardens can contribute to resilience building by nurturing social and ecological diversity, generating and transmitting local ecological knowledge, and creating collective action and self-organization opportunities. Nurturing social cohesion corresponds to mitigating loneliness and enhancing mutual support structures; therefore, this document is related to transformability as well as stability and adaptability.

Rus et al. (2018) conducted a literature review on the holistic assessment of urban system resilience against natural disasters, focusing on earthquakes. Based on the results, a preliminary concept was introduced to assess the seismic resilience of complex urban systems with attention to stability (preparedness and response), recovery, and adaptation. The study also suggested that future research on seismic resilience assessment must consider open space and perform an in-depth examination of possible recovery strategies.

León and March (2014) focused on evacuation and sheltering from tsunamis, which they call rapid resilience, and stated that such resilience can be enhanced by changing urban morphology, which includes street networks and assembly areas. This proposal was quantitatively assessed using an agent-based computer model, which showed significant reductions in total evacuation time. These modifications could also deliver qualitative effects, providing new livable public spaces in the city while helping to maintain the existing tsunami prevention culture. This discussion is related to stability.

Villagra et al. (2016) argued that it is critical to understand how to accommodate the resilience thinking approach in city planning so that urban environments can adapt to extreme natural events. Through a case study in a Chilean urban area, the study evaluated how planning tools contribute to and adversely affect resilience. These tools included the map of civil protection against tsunamis, tsunami and earthquake action plan, regional emergency plan, and communal regulating plan whereas resilience attributes were diversity, redundancy, multifunctionality, and modularity. Finally, the study found that the environmental dimension, which the urban planning tools have failed to integrate, has the greatest influence on the urban resilience of the city studied. This document is related to stability and adaptability. 
Perz et al. (2010), who focused on the stability aspect of community resilience and studied different shocks on normal situations, adopted a resilience approach as an integrative framework to understand various effects of road-paving (infrastructure) on rural areas in the southwestern Amazon. The study highlighted migration activity as an indicator of collective memory retention, which is associated with resilience, and found variations in road-paving effects across areas along with some mediating factors.

c. Summary: main issues regarding the spatial element

The document on nonprivate firms that provide essential infrastructure shed light on how firm-level resilience could be stabilized, a negative effect of which lies in whether hazard seriousness would overwhelm such resilience. One recent and notorious case is the Great East Japan Earthquake, in which the nuclear power plant caused devastating damage to community recovery, as many victims still cannot return home because of the radiation. This specifically pertains to infrastructure resilience and considers how its failure influences community resilience around the infrastructure. This is closely related to land-use planning for location setting and risk assessment with a focus on exposure. With respect to the spatial planning discussion, rational analyses to cope with disasters (therefore, stability) were mainly conducted to find efficient facilities to reduce human loss while also considering adaptability. The built environment regulates other elements by providing spaces for social interactions within and across groups and among actors to enhance competence, diversifying information flow from and to facilities, accelerating economic activities that support community resilience and affect nature through land-use plans or facilities, among others. Even though achievements related to the spatial element hardly mentioned transformability, except for Camps-Calvet et al. (2015), future studies need to examine how the spatial element can promote the transformability of other elements.

\subsubsection{Natural element}

The natural environment greatly affects community livelihood and wellness, as natural disasters occur through interactions between natural (hazard) and human systems (exposure, vulnerability, capacity). Documents that introduced other elements also mentioned the environmental aspect while some focused mainly on this element. Frazier et al. (2013) posed a challenge that most community resilience indexes do not account for the recovery of ecosystem functions after extreme events despite a community's dependence on services provided by the natural environment. By monitoring the recovery of ecosystem functionality (ecological capital) using remote sensing-derived gross primary production and assessing how ecological capital resilience (ecosystem resilience) affects a community's recovery, the results illustrated that ecological capital recovery varies according to land-use type and might take many months to return to full functionality. Such recovery may influence the recovery of certain businesses that rely on ecosystem services such as agriculture, forestry, fisheries, and tourism.

Camp et al. (2015) employed an integrated natural and social science approach to assess the potential mechanisms behind the collapse of estuarine social-ecological 
systems in Florida in the United States. The oyster fishery collapse is the most recent in a series of environmental stressors affecting oyster recruitment and survival, which may have been mediated by both human and environmental factors. The study suggested that the successful restoration and persistence of a viable oyster fishery depend on the implementation of minimal best management practices and spatial closures to harvest, the improvement of environmental knowledge and promotion of episodic learning through enhanced monitoring and experimental management, and continued community engagement to produce adaptable governance that can respond to future unexpected challenges, which are all related to recovery and adaptability.

The natural environment is often considered as a mechanism that brings about shocks against which communities should remain stable, recover, adapt, or transform itself while providing natural resources important to rural livelihood. The natural element is associated with rural economies especially those that heavily depend on natural resources (rural economic resilience).

\subsubsection{Drawbacks of community and equitable resilience}

\section{a. Resilience elasticity and non-normativity}

One of the characteristics of (community) resilience is the ability to bounce back, or the elasticity of the status quo. Moreover, in a discussion of desirable and undesirable resilience, Elemqvist et al. (2019) stated that unlike sustainability, which is considered to be normative, resilience is non-normative. They also stated that the desirability of resilience depends on "of what, to what and for whom" questions regarding reliance. Therefore, the application of resilience requires an understanding of the desired functions of resilience as well as the drivers and feedback loop conditions necessary to transform systems.

Sometimes elasticity of resilience seems to overwhelm another resilience characteristic, transformability, in which present systems change according to new environments. Some documents dealt with this challenge. Manyena and Gordon (2015) concluded that exploring the connections between resilience, fragility, and stabilization might be useful to understand how communities absorb disturbances and reorganize themselves while undergoing change to retain key elements of structure and identity. The findings showed that state fragility results from the breakdown of the social contract between the state and its citizens. While both resilience and stabilization are desirable constructs in reducing fragility, they should be broadly underpinned by agency not only to enhance preventive, anticipatory, absorptive, and adaptive actions but also to generate social transformative capacity where agency is embedded in communities to exercise some power to foster change. Agency in this context means "the capacity of individuals to act independently to make their own free choices" (Brown and Westaway 2011, p. 322). Moreover, Chelleri et al. (2016) provided insights into a range of trade-offs between community resilience attributes and social-ecological vulnerability. Their main contribution was to highlight the need to critically frame multiple threat exposures and adaptive capacity trade-offs. Against the usually positive meaning of resilience, these studies 
urge us to consider who benefits from adaptation or what is positive about it and which trade-off should be accepted and why.

In more specific themes and cases, Béné et al. (2014) evaluated the advantages and drawbacks of resilience in the context of development. Although the review highlighted some positive elements, such as the ability to foster an integrated approach, it also showed the important limitations of resilience, which is not a pro-poor concept in the sense that it does not exclusively apply to, or benefit, the poor. In addition, Wright (2016), in the case of South Wales, explained how the broader context of austerity shapes community resilience against disasters and crises. The study argued that austerity may undermine resilience while helping increase vulnerability, suggesting the need to address these engagement issues and acknowledge the relation between community resilience and broader questions of social, economic, and environmental security. If we accept Elemqvist et al.'s (2019) statement, resilience must be operationalized with other normative concepts.

b. Equitable resilience

Considering the drawbacks of resilience above, Matin et al. (2018) suggested equitable resilience, which can support the development of social-ecological systems that are contextually rooted, responsive to change, and socially just and thus relevant to global sustainability challenges. Furthermore, Cavallo and Ireland (2014) stated that building specified resilience for known risks tends to be a top-down approach while general resilience for unknown risks might involve wider types of residents. Akamani et al. (2015) also emphasized the need for co-management policies to focus on the historical context of community interaction processes that influence access to capital assets and local institutions to successfully promote equitable resilience. Langridge et al. (2006) also suggested that strengthening and diversifying a range of structural and relational mechanisms to access water can enhance a community's resilience against water scarcity.

As discussed in social capital, this topic is related to what resilience should be built and for whom, into which the concept of equitable resilience presents important insights. However, what is equitable is also a matter of discussion influenced by political economy concepts such as neoliberalism, agency in each community, and others. As previously mentioned, resilience may also be in the form of information resilience, institutional resilience, social resilience, economic resilience, infrastructure resilience, and ecosystem resilience, ${ }^{5}$ which all function based on their own targets. Hence, it would also be important to consider how to strike a balance among these types of resilience.

\subsection{Future approaches to community resilience}

The previous section explained how major academic documents approached community resilience in terms of each element, finding contributions to strengthen it. Community resilience is not a standalone concept and should be discussed in

\footnotetext{
5 The term ecological resilience is often used to explain a function of resilience. To differentiate from this, I used ecosystem resilience as in Frazier et al. (2013).
} 


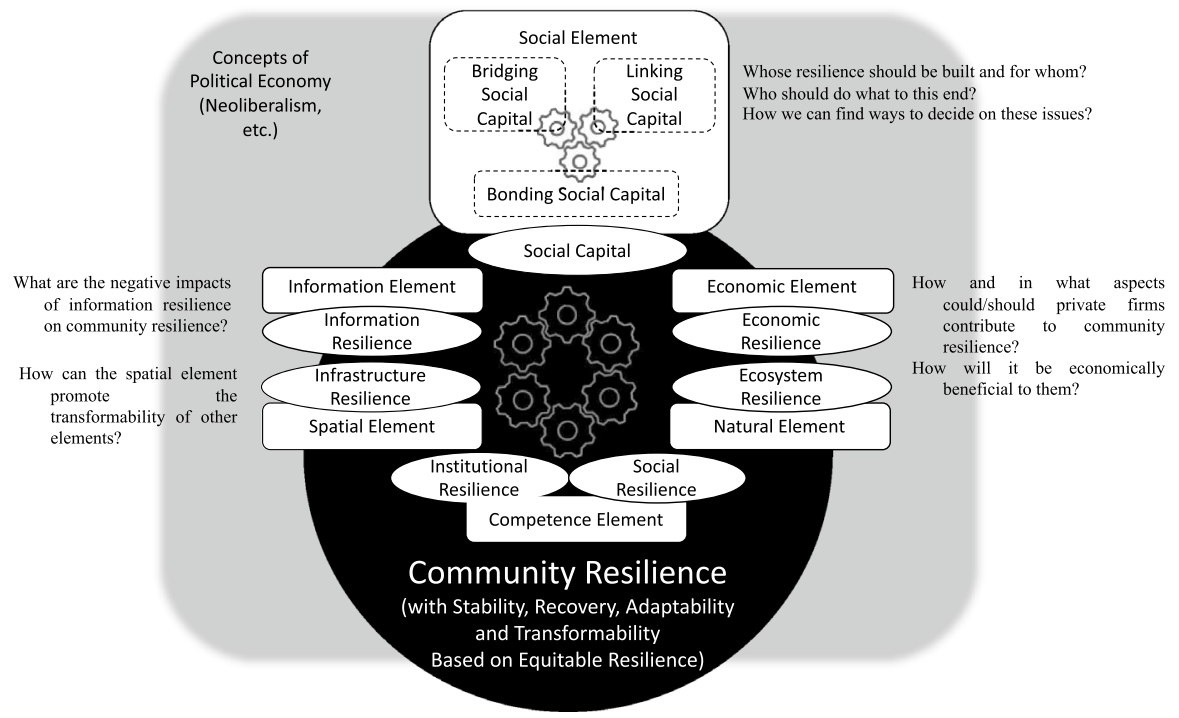

Fig. 7 Conceptual summary of community resilience approaches. Note: This figure shows conceptual relations among community resilience elements, (sub)elements, and related concepts with community resilience at the center, in which gears illustrate harmonies among each element and (sub)element of resilience. Some types of resilience cover part of the elements while others reach beyond them, but for the sake of brevity, they are illustrated the same way

connection with its elements, but it is also true that many documents have scrutinized one or several aspects. Figure 7 summarizes the discussion above. Here I suggest two perspectives that future studies may take regarding community resilience.

\subsubsection{Harmonizing gears of resilience and (Sub)elements peculiar to community resilience}

The first perspective entails harmony among different types of resilience. This document survey found specific resilience attached to the above-mentioned elements: institutional and social resilience, which partially includes the competence element; information resilience for the information element; economic resilience for the economic element; infrastructure resilience for the spatial element; and ecosystem resilience for the natural element. Some resilience types cover parts of the elements while others reach beyond them. Cutter et al. (2014) introduced similar concepts that contain several types of resilience as components of community resilience. ${ }^{6}$ However, in some cases, these types of resilience and (sub)elements may

\footnotetext{
${ }^{6}$ As introduced in this paper, Cutter et al. (2014) deductively constructed the Baseline Resilience Indicators for Communities (BRIC), which is composed of a similar matrix of different resilience types: social resilience, economic resilience, community capital (related to social capital), institutional resilience, housing/infrastructural resilience, and environmental resilience.
} 
work in different ways in between elasticity of some resilience and transformation of another resilience. Areas that have not been affected by disasters are increasingly at risk (Cavallo et al. 2014); whereas, areas that have are suffering from more severe disasters than ever before, which is accelerated by complex social systems. In this situation, studies on community resilience transformability should receive more attention while respecting and preserving a community's unique culture (preferring elasticity). Therefore, this perspective involves studying balances among these types of resilience so that community is transformable in a desired manner. Community resilience may be analyzed based on equitable resilience as desired resilience; and can connect with and exist in its balance with other related resilience types, which is regulated by political economy concepts such as neoliberalism (Fig. 7). Such comprehensive understanding has not been addressed yet, thus the uncertainty of responding to the challenge that even though some elements need transformation, other resilience types would try to keep the status quo, leading to dilemmas if their directions and speed are not compatible with each other. If we imagine community resilience as a car and other types of resilience and (sub)elements as tires, then we could say that some tires are spinning forward at a certain speed while others are spinning slower or even backward, causing the car to lose control. It could be said that this highlights the need to harmonize gears of resilience and sub(elements) peculiar to community resilience. The question of how to strike a balance among these types of resilience to achieve desired community resilience has not yet been discussed, and therefore, needs to be studied further.

\subsubsection{Roles of inactive residents in community resilience}

Another suggestion is based on the fact that community resilience studies often deal with residents who are actively engaged in community activities or all populations collectively in a certain geographical area. Since it is impractical for all populations to be engaged in community activities, we need to not only consider (more) active residents, who are usually the minorities, but also focus on the potential roles of inactive ones, who usually constitute the majority. Inactive residents are not those who are marginalized and unable to join, which is discussed along with equitable resilience in my first suggestion, but rather those who are reluctant to engage despite having access. They should be treated as important actors in building daily community resilience even though they do not participate in community activities. Although community resilience benefits cover (or should cover) all populations, the roles of these residents are different from those of the community leader or residents who are engaged in such actions.

\section{A way forward for community resilience with regional science}

This paper briefly introduced resilience as a buzzword in the academic and professional arenas and identified the need to review the major achievements of community resilience approaches by academic disciplines. The subsequent demonstration of the overall trend of community resilience studies led to a general 
analytical framework for community resilience research. Furthermore, the document survey of influential academic documents based on the framework, focusing on the realm of applying community resilience to practice and societal systems, found current achievements and future perspectives. Finally, I will show the potential contribution of regional science on this topic and challenges that should be dealt with in future studies.

The Asia-Pacific Journal of Regional Science describes its scope, that is, its coverage of regional science, as follows:

(Studies) dedicated to theoretical economics, positive economics, including econometrics and statistical analysis and input-output analysis, CGE (Computable General Equilibrium), Simulation, applied economics, including international economics, regional economics, industrial organization, analysis of governance and institutional issues, law and economics, migration and labor markets, spatial economics, land economics, urban economics, agricultural economics, environmental economics, behavioral economics and spatial analysis, with GIS/RS (Geographic Information Systems/Remote Sensing) data, education economics, sociology, including urban sociology, rural sociology, environmental sociology and educational sociology, as well as traffic engineering (contents in parentheses were added by the author) (Asia-Pacific Journal of Regional Science, n.d.).

It is in the application of community resilience that regional science can contribute to most, and the quote above shows that regional science covers most of the previously discussed community resilience elements. Among its potential contributions, two directions can be identified based on my two suggested perspectives.

First, one must note that the process of building community resilience is not linear. Rather, it is a dynamic and iterative process shaped by forces across spatial and temporal scales (Sharifi 2016). Localized activities are important and, according to Wright (2016), these activities would need to be properly resourced and obtain commitment from the government, corporations, and others to address social, economic, and environmental risks on a broader level. Managing peculiar types of resilience and (sub)elements requires an interdisciplinary approach based on spatial and temporal scales, which is one of the strengths of regional science. As regional science scholars cover most of the elements, collaborative studies that focus on all elements, along with spatial and temporal aspects, may be able to explore comprehensive systems in which community resilience is closely linked to its elements.

The second direction pertains to the transformability of community resilience. Since community resilience can be assessed or evaluated using proxy data of various spatial-temporal patterns, one may detect some factors to promote community transformation, which would be resilience elements or other lock-in effects. Lock-in effects are defined by Wilson et al. (2016) as "drivers that shoehorn certain community decision-making processes into specific pathways or development corridors beyond which certain human decision-making actions become either unthinkable or impossible to implement" (Wilson et al. 2016, p.519). As studies on this issue have been conducted mainly at the micro scale, that is, neighborhood units, regional science could help elevate such an inquiry to the mezzo scale, which involves municipality units such as counties. 
Finally, I will discuss some challenges and limitations with the document survey. First, because community resilience is a new term, many efforts were focused on examining its spirit without using the term itself. Second, this survey included only influential academic documents included in the Web of Science Core Collection. Many journals are not included in this collection, and some journals are only partially included. This survey has also dismissed many others, fewer citations and gray documents emerged, both of which must include novel findings on community resilience approached. This paper also left out efforts to investigate community resilience in academics and practice that the influential documents failed to discuss. Moreover, the resilience of imagined or virtual communities and interest- or kinship-based communities was excluded from the scope of this study. Such communities should be explored in future research. Nevertheless, this paper identified the major achievements and future perspectives of community resilience approaches in terms of geographically constrained communities.

Acknowledgements I would like to express my utmost gratitude to Professor Kenichi Ishibashi (Aichi Gakuin University) who gave me the opportunity to write this survey paper. I would also like to express my appreciation to the two anonymous reviewers who carefully read my essay and provided beneficial comments. However, the author is of course solely responsible for the content of the paper.

Funding This work was supported by JSPS KAKENHI Grant Number 18K13972, Program Support for Formation of Research Base (Institute of Disaster Mitigation for Urban Cultural Heritage, Ritsumeikan University), and the program for major research institute at the Kinugasa Research Institute (Institute of Disaster Mitigation for Urban Cultural Heritage, Ritsumeikan University).

\section{Declarations}

Conflict of interest The author has no conflicts of interest to declare.

Open Access This article is licensed under a Creative Commons Attribution 4.0 International License, which permits use, sharing, adaptation, distribution and reproduction in any medium or format, as long as you give appropriate credit to the original author(s) and the source, provide a link to the Creative Commons licence, and indicate if changes were made. The images or other third party material in this article are included in the article's Creative Commons licence, unless indicated otherwise in a credit line to the material. If material is not included in the article's Creative Commons licence and your intended use is not permitted by statutory regulation or exceeds the permitted use, you will need to obtain permission directly from the copyright holder. To view a copy of this licence, visit http://creativecommons.org/licen ses/by/4.0/.

\section{References}

Abramson DM, Grattan LM, Mayer B et al (2015) The resilience activation framework: a conceptual model of how access to social resources promotes adaptation and rapid recovery in post-disaster settings. J Behav Health Serv Res 42:42-57. https://doi.org/10.1007/s11414-014-9410-2

Adger WN (2000) Social and ecological resilience: are they related? Prog Hum Geogr 24(3):347-364. https://doi.org/10.1191/030913200701540465

Ahmed B, Kelman I, Fehr HK, Saha M (2016) Community resilience to cyclone disasters in coastal Bangladesh. Sustainability 8:805. https://doi.org/10.3390/su8080805 
Akamani K (2015) Hall TE (2015) Determinants of the process and outcomes of household participation in collaborative forest management in Ghana: a quantitative test of a community resilience model. J Environ Manage 147:1-11

Akamani K, Wilson PI, Hall TE (2015) Barriers to collaborative forest management and implications for building the resilience of forest-dependent communities in the Ashanti region of Ghana. J Environ Manag 151:11-21. https://doi.org/10.1016/j.jenvman.2014.12.006

Aldrich DP, Meyer MA (2015) Social capital and community resilience. Am Behav Sci 59(2):254269. https://doi.org/10.1177/0002764214550299

Aldunce P, Beilin R, Handmer J, Howden M (2016) Stakeholder participation in building resilience to disasters in a changing climate. Environ Hazards 15(1):58-73. https://doi.org/10.1080/17477 891.2015.1134427

Alexander DE (2013) Resilience and disaster risk reduction: an etymological journey. Nat Hazards Earth Syst Sci 13:2707-2716. https://doi.org/10.5194/nhess-13-2707-2013

Archer D, Marome W, Natakun B, Mabangyang P, Phanthuwongpakdee N (2020) The role of collective and individual assets in building urban community resilience. Int $\mathrm{J}$ Urban Sustain Dev 12:169-186. https://doi.org/10.1080/19463138.2019.1671425

Ashmore HF, Farrington HJ, Skerratt S (2015) Superfast broadband and rural community resilience: examining the rural need for speed. Scott Geograph J 131(3-4):265-278. https://doi.org/10. 1080/14702541.2014.978808

Asia-Pacific Journal of Regional Science (2020) Asia-Pacific Journal of Regional Science. AsiaPacific Journal of Regional Science. https://www.springer.com/journal/41685. Accessed 1 October 2020

Ayyub BM (2014) Systems resilience for multihazard environments: definition, metrics, and valuation for decision making. Risk Anal 34:340-355. https://doi.org/10.1111/risa.12093

Baek JS, Meroni A, Manzini E (2015) A socio-technical approach to design for community resilience: a framework for analysis and design goal forming. Des Stud 40:60-84. https://doi.org/10. 1016/j.destud.2015.06.004

Bahadur AV, Ibrahim M, Tanner T (2010) The resilience renaissance? Unpacking of resilience for tackling climate change and disasters. Institute of Development Studies. https://opendocs.ids.ac. uk/opendocs/bitstream/handle/20.500.12413/2368/The\%20resilience\%20renaissance.pdf?seque nce $=1 \&$ is Allowed $=y$. Accessed 1 October 2020

Barnes ML, Wang P, Cinner JE et al (2020) Social determinants of adaptive and transformative responses to climate change. Nat Clim Change 10:823-828. https://doi.org/10.1038/ s41558-020-0871-4

Barrios RE (2014) 'Here, I'm not at ease': anthropological perspectives on community resilience. Disasters 38:329-350. https://doi.org/10.1111/disa.12044

Barrios R (2017) Governing affect: neoliberalism and disaster reconstruction. University of Nebraska Press. http://www.jstor.org/stable/j.ctt1mtz7p9. Accessed 1 Oct 2020

Béné C, Newsham A, Davies M, Ulrichs M, Godfrey-Wood R (2014) Review article: resilience, poverty and development. J Int Dev 26:598-623. https://doi.org/10.1002/jid.2992

Berkes F, Ross H (2013) Community resilience: toward an integrated approach. Soc Nat Resour 26(1):520. https://doi.org/10.1080/08941920.2012.736605

Bhandari H, Yasunobu K (2009) What is social capital?: a comprehensive review of the concept. Asian J Soc Sci 37(3):480-510. https://doi.org/10.1163/156853109X436847

Brown K (2014) Global environmental change I: a social turn for resilience? Prog Hum Geogr 38(1):107117. https://doi.org/10.1177/0309132513498837

Brown K, Westaway E (2011) Agency, capacity, and resilience to environmental change: lessons from human development, well-being, and disasters. Annu Rev Environ Resour 36(1):321-342. https:// doi.org/10.1146/annurev-environ-052610-092905

Bruneau M, Chan SE, Eguchi RT et al (2003) A framework to quantitatively assess and enhance the seismic resilience of communities. Earthq Spectra 19(4):733-752. https://doi.org/10.1193/1.1623497

Bulley D (2013) Producing and governing community (through) resilience. Politics 33(4):265-275. https://doi.org/10.1111/1467-9256.12025

Burton CG (2015) A validation of metrics for community resilience to natural hazards and disasters using the recovery from Hurricane Katrina as a case study. Ann Assoc Am Geogr 105(1):67-86. https:// doi.org/10.1080/00045608.2014.960039 
Cagney KA, Sterrett D, Benz J, Tompson T (2016) Social resources and community resilience in the wake of superstorm Sandy. PLoS ONE 11(8):e0160824. https://doi.org/10.1371/journal.pone. 0160824

Camp EV, Pine WE III, Havens K et al (2015) Collapse of a historic oyster fishery: diagnosing causes and identifying paths toward increased resilience. Ecol Soc 20(3):45. https://doi.org/10.5751/ ES-07821-200345

Camps-Calvet M, Langemeyer J, Calvet-Mir L, Gómez-Baggethun E, March H (2015) Sowing resilience and contestation in times of crises: the case of urban gardening movements in Barcelona. PARTECIPAZIONE E CONFLITTO 8(2):417-442. https://doi.org/10.1285/i20356609v8i2p417

Castleden M, McKee M, Murray V, Leonardi G (2011) Resilience thinking in health protection. J Public Health 33(3):369-377. https://doi.org/10.1093/pubmed/fdr027

Cavallo A, Ireland V (2014) Preparing for complex interdependent risks: a system of systems approach to building disaster resilience. Int J Disaster Risk Reduct 9:181-193. https://doi.org/10.1016/j.ijdrr. 2014.05.001

Chandra A, Williams M, Plough A, Stayton A, Wells KB, Horta M, Tang J (2013) Getting actionable about community resilience: the Los Angeles county community disaster resilience project. Am J Public Health 103(7):1181-1189. https://doi.org/10.2105/AJPH.2013.301270

Chaney PL, Weaver GS, Youngblood SA, Pitts K (2013) Household preparedness for tornado hazards: the 2011 disaster in DeKalb County, Alabama. Weather, Clima Soc 5(4):345-358. https://doi.org/ 10.1175/WCAS-D-12-00046.1

Chelleri L, Olazabal M (2012) Multidisciplinary perspectives on urban resilience: Workshop Report $1^{\text {st }}$ edition. BC3, Basque Centre for Climate Change, Bilbao.

Chelleri L, Minucci G, Skrimizea E (2016) Does community resilience decrease social-ecological vulnerability?: Adaptation pathways trade-off in the Bolivian Altiplano. Reg Environ Change 16(8):2229-2241. https://doi.org/10.1007/s10113-016-1046-8

Coaffee J, Fussey P (2015) Constructing resilience through security and surveillance: the politics, practices and tensions of security-driven resilience. Secur Dialogue 46(1):86-105. https://doi.org/10. $1177 / 0967010614557884$

Cohen O, Goldberg A, Lahad M, Aharonson-Daniel L (2017) Building resilience: the relationship between information provided by municipal authorities during emergency situations and community resilience. Technol Forecast Soc Change 121:119-125. https://doi.org/10.1016/j.techfore. 2016.11.008

Colten CE, Hay J, Giancarlo A (2012) Community resilience and oil spills in coastal Louisiana. Ecol Soc 17(3):5. https://doi.org/10.5751/ES-05047-170305

Cretney RM (2016) Local responses to disaster. Disaster Prev Manag 25(1): 27-40. https://doi.org/10. 1108/DPM-02-2015-0043

Cutter SL, Barnes L, Berry M, Burton C, Evans E, Tate E, Webb J (2008) A place-based model for understanding community resilience to natural disasters. Glob Environ Chang 18(4):598-606. https://doi.org/10.1016/j.gloenvcha.2008.07.013

Cutter SL, Ash KD, Emrich CT (2014) The geographies of community disaster resilience. Glob Environ Change 29:65-77. https://doi.org/10.1016/j.gloenvcha.2014.08.005

Cutter SL, Ash KD, Emrich CT (2016) Urban-rural differences in disaster resilience. Ann Am Assoc Geogr 106(6):1236-1252. https://doi.org/10.1080/24694452.2016.1194740

CutterBurtonEmrich SLCGCT (2010) Disaster resilience indicators for benchmarking baseline conditions. J Homel Secur Emerg Manag 7(1):51. https://doi.org/10.2202/1547-7355.1732

Dabson B (2015) Planning for a more resilience future: a guide to regional approaches. NADO (National Association of Development Organization) Research Foundation, Washington DC

D’Agostino AL, Sovacool BK (2011) Sewing climate-resilient seeds: implementing climate change adaptation best practices in rural Cambodia. Mitig Adapt Strat Glob Change 16(6):699-720. https://doi. org/10.1007/s11027-011-9289-7

Elmqvist T, Andersson E, Frantzeskaki N et al (2019) Sustainability and resilience for transformation in the urban century. Nat Sustain 2:267-273. https://doi.org/10.1038/s41893-019-0250-1

Engel K, Frerks G, Velotti L, Warner J, Weijs B (2014) Flood disaster subcultures in the Netherlands: the parishes of Borgharen and Itteren. Nat Hazards 73(2):859-882. https://doi.org/10.1007/ s11069-014-1116-5

Finkbeiner EM (2015) The role of diversification in dynamic small-scale fisheries: lessons from Baja California Sur, Mexico. Glob Environ Change 32:139-152. https://doi.org/10.1016/j.gloenvcha. 2015.03.009 
Fischer A, McKee A (2017) A question of capacities?: community resilience and empowerment between assets, abilities and relationships. J Rural Stud 54:187-197. https://doi.org/10.1016/j.jrurstud.2017. 06.020

Fois F, Forino G (2014) The self-built ecovillage in L'Aquila, Italy: community resilience as a grassroots response to environmental shock. Disasters 38(4):719-739. https://doi.org/10.1111/disa.12080

Frazier AE, Renschler CS, Miles SB (2013) Evaluating post-disaster ecosystem resilience using MODIS GPP data. Int J Appl Earth Obs Geoinf 21:43-52. https://doi.org/10.1016/j.jag.2012.07.019

Freitag RC, Abramson DB, Chalana M, Dixon M (2014) Whole community resilience: an asset-based approach to enhancing adaptive capacity before a disruption. J Am Plann Assoc 80(4):324-335. https://doi.org/10.1080/01944363.2014.990480

Goldstein S, Brooks RB (2006) Handbook of resilience in children. Springer, New York

Gómez-Baggethun E, Reyes-García V, Olsson P, Montes C (2012) Traditional ecological knowledge and community resilience to environmental extremes: a case study in Doñana, SW Spain. Glob Environ Change 22(3):640-650. https://doi.org/10.1016/j.gloenvcha.2012.02.005

Grace D, Sen B (2013) Community resilience and the role of the public library. Libr Trends 61(3):513541. https://doi.org/10.1353/lib.2013.0008

Hawkins LR, Maurer K (2010) Bonding, bridging and linking: how social capital operated in New Orleans following Hurricane Katrina. Br J Soc Work 40(6):1777-1793. https://doi.org/10.1093/ bjsw/bcp087

Herrfahrdt-Pähle E, Pahl-Wostl C (2012) Continuity and change in social-ecological systems: the role of institutional resilience. Ecology and Society 17(2). http://www.jstor.org/stable/26269033. Accessed 1 Oct 2020

Holling CS (1973) Resilience and stability of ecological systems. Annu Rev Ecol Syst 4:1-23. https://doi. org/10.1146/annurev.es.04.110173.000245

Hosseini S, Barker K, Ramirez-Marquez JE (2016) A review of definitions and measures of system resilience. Reliab Eng Syst Saf 145:47-61. https://doi.org/10.1016/j.ress.2015.08.006

Houston JB, Hawthorne J, Perreault MF et al (2015) Social media and disasters: a functional framework for social media use in disaster planning, response, and research. Disasters 39(1):1-22. https://doi. org/10.1111/disa.12092

Iacoviello BM, Charney DS (2014) Psychosocial facets of resilience: implications for preventing posttrauma psychopathology, treating trauma survivors, and enhancing community resilience. Eur $\mathbf{J}$ Psychotraumatol 5(1):23970. https://doi.org/10.3402/ejpt.v5.23970

Joerin J, Shaw R, Takeuchi Y, Krishnamurthy R (2012) Assessing community resilience to climaterelated disasters in Chennai, India. Int J Disaster Risk Reduct 1:44-54. https://doi.org/10.1016/j. ijdrr.2012.05.006

Jordan E, Javernick-Will A, Tierney K (2016) Post-tsunami recovery in Tamil Nadu, India: combined social and infrastructural outcomes. Nat Hazards 84(2):1327-1347. https://doi.org/10.1007/ s11069-016-2489-4

Kim H, Marcouiller DW (2016) Natural disaster response, community resilience, and economic capacity: a case study of coastal Florida. Soc Nat Resour 29(8):981-997. https://doi.org/10.1080/08941920. 2015.1080336

Langridge R, Christian-Smith J, and Lohse AK (2006) Access and resilience: analyzing the construction of social resilience to the threat of water scarcity. Ecology and Society 11(2): 18. http://www.ecolo gyandsociety.org/vol11/iss2/art18/. Accessed 1 Oct 2020

Leichenko R (2011) Climate change and urban resilience. CurrOpin EnvironSustain 3(3):164-168. https://doi.org/10.1016/j.cosust.2010.12.014

León J, March A (2014) Urban morphology as a tool for supporting tsunami rapid resilience: a case study of Talcahuano, Chile. Habitat Int 43:250-262. https://doi.org/10.1016/j.habitatint.2014.04.006

Leydesdorff L, Park HW (2017) Full and fractional counting in bibliometric networks. J Inf 11(1):117120. https://doi.org/10.1016/j.joi.2016.11.007

Linnenluecke MK, Macknight B (2017) Community resilience to natural disasters: the role of disaster entrepreneurship. J Enterp Communities 11(1):166-185. https://doi.org/10.1108/ JEC-01-2015-0005

Lloyd A (2015) Stranger in a strange land; enabling information resilience in resettlement landscapes. Journal of Documentation 71(5):1029-1042. https://doi.org/10.1108/JD-04-2014-0065

Madsen W, O'Mullan C (2016) Perceptions of community resilience after natural disaster in a rural Australian town. J Community Psychol 44(3):277-292. https://doi.org/10.1002/jcop.21764 
Magis K (2010) Community resilience: an Indicator of social sustainability. Soc Nat Resour 23(5):401416. https://doi.org/10.1080/08941920903305674

Manyena CB, Gordon S (2015) Bridging the concepts of resilience, fragility and stabilisation. Disaster Prev Manag 24(1):38-52. https://doi.org/10.1108/DPM-04-2014-0075

Manyena B, Machingura F, O'Keefe P (2019) Disaster resilience integrated framework for transformation (DRIFT): a new approach to theorising and operationalising resilience. World Dev 123:104587. https://doi.org/10.1016/j.worlddev.2019.06.011

Matin N, Forrester J, Ensor J (2018) What is equitable resilience? World Dev 109:197-205. https://doi. org/10.1016/j.worlddev.2018.04.020

McEwen L, Garde-Hansen J, Holmes A, Jones O, Krause F (2017) Sustainable flood memories, lay knowledges and the development of community resilience to future flood risk. Trans Inst Br Geogr 42(1):14-28. https://doi.org/10.1111/tran.12149

McKnight B, Linnenluecke MK (2016) How firm responses to natural disasters strengthen community resilience: a stakeholder-based perspective. Organ Environ 29(3):290-307. https://doi.org/10.1177/ 1086026616629794

McMillen H, Ticktin T, Springer HK (2017) The future is behind us: traditional ecological knowledge and resilience over time on Hawai' ${ }^{i}$ Island. Reg Environ Change 17(2):579-592. https://doi.org/10. 1007/s10113-016-1032-1

Miller Hesed DC, Paolisso M (2015) Cultural knowledge and local vulnerability in African American communities. Nature Clim Change 5:683-687. https://doi.org/10.1038/nclimate2668

Mulligan M, Steele W, Rickards L, Fünfgeld H (2016) Keywords in planning: what do we mean by 'community resilience'? Int Plan Stud 21(4):348-361. https://doi.org/10.1080/13563475.2016. 1155974

Murphy BL (2007) Locating social capital in resilient community-level emergency management. Nat Hazards 41(2):297-315. https://doi.org/10.1007/s11069-006-9037-6

Norris FH, Stevens SP, Pfefferbaum B, Wyche KF, Pfefferbaum RL (2008) Community resilience as a metaphor, theory, set of capacities, and strategy for disaster readiness. Am J Community Psychol 41(1-2):127-150. https://doi.org/10.1007/s10464-007-9156-6

O'Sullivan TL, Kuziemsky CE, Toal-Sullivan D, Corneil W (2013) Unraveling the complexities of disaster management: a framework for critical social infrastructure to promote population health and resilience. Soc Sci Med 93:238-246. https://doi.org/10.1016/j.socscimed.2012.07.040

Olsson L, Jerneck A, Thoren H, Persson J, O’Byrne D (2015) Why resilience is unappealing to social science: theoretical and empirical investigations of the scientific use of resilience. Sci Adv 1(4):e1400217. https://doi.org/10.1126/sciadv.1400217

Ozanne LK, Ozanne JL (2016) How alternative consumer markets can build community resiliency. Eur J Mark 50(3-4):330-357. https://doi.org/10.1108/EJM-12-2014-0802

Palekiene O, Simanaviciene Z, Bruneckiene J (2015) The application of resilience concept in the regional development context. Proc Soc Behav Sci 213:179-184. https://doi.org/10.1016/j. sbspro.2015.11.423

Papadopoulos T, Gunasekaran A, Dubey R, Altay N, Childe SJ, Fosso-Wamba S (2017) The role of Big Data in explaining disaster resilience in supply chains for sustainability. J Clean Prod 142:1108-1118. https://doi.org/10.1016/j.jclepro.2016.03.059

Perianes-Rodriguez A, Waltman L, van Eck NJ (2016) Constructing bibliometric networks: a comparison between full and fractional counting. J Informet 10(4):1178-1195. https://doi.org/10. 1016/j.joi.2016.10.006

Perz SG, Cabrera L, Carvalho LA, Castillo J, Barnes G (2010) Global economic integration and local community resilience: road paving and rural demographic change in the Southwestern Amazon. Rural Sociol 75(2):300-325. https://doi.org/10.1111/j.1549-0831.2009.00008.x

Plough A, Fielding JE, Chandra A et al (2013) Building community disaster resilience: perspectives from a large urban county department of public health. Am J Public Health 103(7):1190-1197. https://doi.org/10.2105/AJPH.2013.301268

Quinlan AE, Berbés-Blázquez M, Haider LJ, Peterson GD (2016) Measuring and assessing resilience: broadening understanding through multiple disciplinary perspectives. J Appl Ecol 53(3):677687. https://doi.org/10.1111/1365-2664.12550

Richardson JL (1980) Commentary: the organismic community: resilience of an embattled ecological concept. Bioscience 30(7):465-471. https://doi.org/10.2307/1307949 
Roberts E, Townsend L (2016) The contribution of the creative economy to the resilience of rural communities: exploring cultural and digital capital. Sociol Rural 56(2):197-219. https://doi.org/ 10.1111/soru. 12075

Roberts E, Anderson BA, Skerratt S, Farrington J (2017) A review of the rural-digital policy agenda from a community resilience perspective. J Rural Stud 54:372-385. https://doi.org/10.1016/j. jrurstud.2016.03.001

Rogers P (2013) Rethinking resilience: articulating community and the UK riots. Politics 33(4):322333. https://doi.org/10.1111/1467-9256.12033

Rus K, Kilar V, Koren D (2018) Resilience assessment of complex urban systems to natural disasters: a new literature review. Int J Disaster Risk Reduct 31:311-330. https://doi.org/10.1016/j.ijdrr. 2018.05.015

Sadri AM, Ukkusuri SV, Lee S et al (2018) The role of social capital, personal networks, and emergency responders in post-disaster recovery and resilience: a study of rural communities in Indiana. Nat Hazards 90(3):1377-1406. https://doi.org/10.1007/s11069-017-3103-0

Saunders WSA, Becker JS (2015) A discussion of resilience and sustainability: land use planning recovery from the Canterbury earthquake sequence, New Zealand. Int J Disaster Risk Reduct 14:73-81. https://doi.org/10.1016/j.ijdrr.2015.01.013

Sharifi A (2016) A critical review of selected tools for assessing community resilience. Ecol Ind 69:629-647. https://doi.org/10.1016/j.ecolind.2016.05.023

Sharifi A, Yamagata Y (2016) Principles and criteria for assessing urban energy resilience: a literature review. Renew Sustain Energy Rev 60:1654-1677. https://doi.org/10.1016/j.rser.2016.03.028

Shava S, Krasny ME, Tidball KG, Zazu C (2010) Agricultural knowledge in urban and resettled communities: applications to social-ecological resilience and environmental education. Environ Educ Res 16(5-6):575-589. https://doi.org/10.1080/13504622.2010.505436

Sherrieb K, Norris FH, Galea S (2010) Measuring capacities for community resilience. Soc Indic Res 99(2):227-247. https://doi.org/10.1007/s11205-010-9576-9

Singh-Peterson L, Salmon P, Baldwin C, Goode N (2015) Deconstructing the concept of shared responsibility for disaster resilience: a Sunshine Coast case study. Australia Natural Hazards 79(2):755774. https://doi.org/10.1007/s11069-015-1871-y

Smith JW, Moore RL, Anderson DH, Siderelis C (2012) Community resilience in Southern Appalachia: a theoretical framework and three case studies. Hum Ecol 40(3):341-353. https://doi.org/10.1007/ s10745-012-9470-y

Sonn CC, Fisher AT (1998) Sense of community: community resilient responses to oppression and change. J Community Psychol 26(5):457-472. https://doi.org/10.1002/(SICI)1520-6629(199809) 26:5\%3c457::AID-JCOP5\%3e3.0.CO;2-O

Steiner A (2016) Assessing the effectiveness of a capacity building intervention in empowering hardto-reach communities. J Community Pract 24(3):235-263. https://doi.org/10.1080/10705422.2016. 1201561

Steiner A, Atterton J (2015) Exploring the contribution of rural enterprises to local resilience. J Rural Stud 40:30-45. https://doi.org/10.1016/j.jrurstud.2015.05.004

Toriya M (2017) Comparison of tools for research performance analysis. J Inf Sci Technol Assoc 67(4):171-178. https://doi.org/10.18919/jkg.67.4_171(inJapanese)

Townshend I, Awosoga O, Kulig J, Fan H (2015) Social cohesion and resilience across communities that have experienced a disaster. Nat Hazards 76(2):913-938. https://doi.org/10.1007/ s11069-014-1526-4

Toyoda Y (2020) A Framework of simulation and gaming for enhancing community resilience against large-scale earthquakes: application for achievements in Japan. Simul Gaming 51(2):180-211. https://doi.org/10.1177/1046878119899424

Toyoda Y, Kanegae H (2014) A Community evacuation planning model against urban earthquakes. Reg Sci Policy Pract 6(3):231-249. https://doi.org/10.1111/rsp3.12036

Tsai C-H, Wu T-C, Wal G, Linliu S-C (2016) Perceptions of tourism impacts and community resilience to natural disasters. Tour Geogr 18(2):152-173. https://doi.org/10.1080/14616688.2016.1149875

Usamah M, Handmer J, Mitchell D, Ahmed I (2014) Can the vulnerable be resilient?: co-existence of vulnerability and disaster resilience: Informal settlements in the Philippines. Int J Disaster Risk Reduct 10:178-189. https://doi.org/10.1016/j.ijdrr.2014.08.007

Van Eck NJ, Waltma L (2017) Citation-based clustering of publications using CitNetExplorer and VOSviewer. Scientometrics 111:1053-1070. https://doi.org/10.1007/s11192-017-2300-7 
Van Eck NJ, Waltman L (2014) Visualizing bibliometric networks. In: Ding Y, Rousseau R, Wolfram D (eds) Measuring scholarly impact: methods and practice. Springer. https://doi.org/10.1007/978-3319-10377-8_13

Veil SR, Bishop BW (2014) Opportunities and challenges for public libraries to enhance community resilience. Risk Anal 34(4):721-734. https://doi.org/10.1111/risa.12130

Villagra P, Herrmann G, Quintana C, Sepúlveda RD (2016) Resilience thinking and urban planning in a coastal environment at risks of tsunamis: the case study of Mehuín. Chile Rev Geogr Norte Gd 64:63-82. https://doi.org/10.4067/S0718-34022016000200006

Wells KB, Tang J, Lizaola E et al (2013) Applying community engagement to disaster planning: developing the vision and design for the Los Angeles County community disaster resilience initiative. Am J Public Health 103(7):1172-1180. https://doi.org/10.2105/AJPH.2013.301407

Welsh M (2014) Resilience and responsibility: governing uncertainty in a complex world. Geogr J 180(1):15-26. https://doi.org/10.1111/geoj.12012

Wickes R, Zahnow R, Taylor M, Piquero AR (2015) Neighborhood structure, social capital, and community resilience: longitudinal evidence from the 2011 Brisbane flood disaster. Soc Sci Q 96(2):330353. https://doi.org/10.1111/ssqu. 12144

Wilson GA (2010) Multifunctional 'quality' and rural community resilience. Trans Inst Br Geogr 35(3):364-381. https://doi.org/10.1111/j.1475-5661.2010.00391.x

Wilson GA (2012) Community resilience, globalization, and transitional pathways of decision-making. Geoforum 43(6):1218-1231. https://doi.org/10.1016/j.geoforum.2012.03.008

Wilson GA (2013a) Community resilience, social memory and the post-2010 Christchurch (New Zealand) earthquakes. Area 45(2):207-215. https://doi.org/10.1111/area.12012

Wilson GA (2013b) Community resilience, policy corridors and the policy challenge. Land Use Policy 31:298-310. https://doi.org/10.1016/j.landusepol.2012.07.011

Wilson GA (2015) Community resilience and social memory. Environ Values 24(2):227-257. https://doi. org/10.3197/096327114x13947900182157

Wilson G, Quaranta G, Kelly C, Salvia R (2016) Community resilience, land degradation and endogenous lock-in effects: evidence from the Alento region, Campania, Italy. J Environ Plan Manag 59(3):518-537. https://doi.org/10.1080/09640568.2015.1024306

Wilson GA, Kelly CL, Briassoulis H et al (2017) Social memory and the resilience of communities affected by land degradation. Land Degrad Dev 28(2):383-400. https://doi.org/10.1002/ldr.2669

Wright K (2016) Resilient communities?: experiences of risk and resilience in a time of austerity. Intl J Disaster Risk Reduct 18:154-161. https://doi.org/10.1016/j.ijdrr.2016.06.003

Zhou H, Wang J, Wan J, Jia H (2010) Resilience to natural hazards: a geographic perspective. Nat Hazards 53(1):21-41. https://doi.org/10.1007/s11069-009-9407-y

Zou L, Lam NSN, Cai H, Qiang Y (2018) Mining twitter data for improved understanding of disaster resilience. Ann Am Assoc Geogr 108(5):1422-1441. https://doi.org/10.1080/24694452.2017. 1421897

Publisher's Note Springer Nature remains neutral with regard to jurisdictional claims in published maps and institutional affiliations. 